\title{
Theoretical Study on the Characteristics of Critical Heat Flux in Rectangular Channel of Natural Circulation under Motion Conditions
}

\author{
Mengmeng Xi, ${ }^{1}$ Rong Cai, ${ }^{1}$ Xiao Chu, ${ }^{1}$ Fan Yang, ${ }^{1}$ Xu Ran, ${ }^{1}$ Zhifang Qiu, ${ }^{1}$ Jian Deng $\mathbb{D},{ }^{1}$ \\ and Wenxi Tian ${ }^{2}$ \\ ${ }^{1}$ Science and Technology on Reactor System Design Technology Laboratory, Nuclear Power Institute of China, \\ Chengdu 610213, China \\ ${ }^{2}$ State Key Laboratory of Multiphase Flow in Power Engineering, Department of Nuclear Science and Technology, \\ Xi'an Jiaotong University, Xi'an 710049, China
}

Correspondence should be addressed to Jian Deng; dj123dj456dj@126.com

Received 23 November 2019; Revised 11 February 2020; Accepted 11 May 2020; Published 2 September 2020

Academic Editor: Arkady Serikov

Copyright (C) 2020 Mengmeng Xi et al. This is an open access article distributed under the Creative Commons Attribution License, which permits unrestricted use, distribution, and reproduction in any medium, provided the original work is properly cited.

With the wide application of sea-based reactors, the impact of ocean conditions on the safety performance of reactors has gradually attracted attention. In this paper, by establishing the thermal hydraulic transient analysis model and the critical heat flux (CHF) model of natural circulation system, the CHF characteristics in the rectangular channel of natural self-feedback conditions under ocean conditions are studied. The results show that the additional acceleration field generated by ocean conditions will affect the thermal hydraulic parameters of the natural circulation system, that is, the external macroscopic thermal hydraulic field. On the other hand, the boiling crisis mechanism will be affected, that is, the force on the bubble and the thickness of the liquid film. Within the parameters of the study, ocean conditions have a great impact on CHF of natural circulation, and the maximum degradation of $\mathrm{CHF}$ is about $45 \%$. The obtained analysis results are significant to the improvement of design and safety operation of the reactor system.

\section{Introduction}

Critical heat flux $(\mathrm{CHF})$ is one of the important safety guidelines for reactor thermal hydraulic design. The $\mathrm{CHF}$ is the heat flux when the heat transfer on the surface of the nuclear fuel element deteriorates. It is the result of the transition of the coolant flow boiling mechanism. According to the parameters such as the enthalpy and vapor content of the fluid, the DNB type and the Dryout type of boiling crisis phenomena may appear in the tube. If the boiling crisis occurs on the surface of the fuel element of the reactor, the surface temperature of the fuel element will be too high, causing the heated wall to burn out, and the radioactive material leaks, causing serious operational accidents, directly affecting the safety of the reactor. Compared with conventional energypowered propulsion ships, the performance of nuclear- powered propulsion ships has been greatly improved, and the maneuverability, concealability, and endurance of nuclearpowered ships have been greatly improved. In order to meet maneuverability, ship reactors need to change power frequently, and if necessary, natural circulation is a reliable way to remove heat without any driving components such as pumps.

With the application of sea-based reactors such as marine nuclear power platforms, the impact of ocean conditions on the operation of the reactor has gradually attracted attention. Isshiki [1] studied the effects of heaving and heeling on the CHF under normal pressure and low flow conditions. The results show that the CHF decreases linearly with the increase of the acceleration. The experimental observation of the ocean conditions causes the bubble distribution changes, and a semiempirical relationship is 
obtained by introducing the fluctuation influence factor and the heaving influence factor. OTSUJI et al. [2-4] used Freon 113 to study the effect of oscillating acceleration on the CHF of forced convection. It has been found that the acceleration of oscillating generally reduces the $\mathrm{CHF}$, and the cavitation and flow fluctuation caused by oscillating acceleration will cause CHF to appear in advance, and OTSUJI believes that the mechanism of this CHF phenomenon is the evaporation of the liquid film under the steam block. There were only a few cases of CHF experiments under ocean conditions [5]. Due to the complexity of ocean conditions, researchers usually calculate CHF by modifying empirical relationships.

There are many CHF prediction methods including empirical correlations, look-up tables, and various mechanistic models. Although $\mathrm{CHF}$ in boiling flow pipe was investigated by lots of researchers [6-10], they are all under forced circulation system and stationary condition. Umekawa et al. [11] experimentally and numerically studied Dryout $\mathrm{CHF}$ in a boiling channel under oscillatory flow condition. The numerical simulation represents well the transient behavior of the Dryout under the oscillatory flow condition. Geping et al. [12] experimentally studied CHF and Dryout point in narrow annuli pipe, and based on experiment data, a new correlation is developed. Celata et al. [13] presents an analytical model for the prediction of the CHF in water saturated flow boiling in round vertical and uniformly heated pipes. The model shows a quite good CHF predictive capability for selected experimental points. Du et al. [6] investigated the $\mathrm{CHF}$ in a vertical narrow rectangular channel. The influences of system pressure, inlet mass flux, and channel size on $\mathrm{CHF}$ in rectangular channels are analyzed. The $\mathrm{CHF}$ can be predicted well, compared with experimental data. Jayanti and Valette [14] presented a set of closure relations of a onedimensional three-phase calculation methodology for the prediction of Dryout and post-Dryout heat transfer at high pressure conditions and developed new correlations for the interfacial friction factor between the liquid film and the gas phase, for the droplet diameter and for the transition to annular flow. Su et al. [10] developed a theoretical three-fluid model for predicting annular upward flow in vertical narrow annuli with bilateral heating. The present model can be used to calculate the $\mathrm{CHF}$ and critical quality in narrow annular gap.

It can be seen from the above-mentioned research status at home and abroad that natural circulation, as an important form of circulation in nuclear power systems, is of great significance in the operation of reactors. The influence of ocean conditions on natural circulation is more significant than that on forced circulation. Under ocean conditions, the value of the critical heat flux has decreased significantly compared to the value under land-based conditions, and it will bring serious challenges to the reactor safety. The mechanism of CHF of natural circulation under ocean conditions is more complicated, but related studies are rarely published.

This paper takes the natural circulation system under ocean conditions as the research object, establishes a reasonable mathematical physics model for the natural circulation system structure and dynamic self-feedback characteristics, and develops the analysis program using the Fortran 90 programming language. The thermal hydraulic characteristics of the natural circulation system and the $\mathrm{CHF}$ characteristics under natural circulation conditions are calculated and analyzed.

\section{Mathematical Model}

The schematic structure of the natural circulation loop is shown in Figure 1. The natural circulation loop includes a heated section, a condenser, a preheater, a pressurizer, and pipes.

The basic field model for natural circulation is based on fundamental conservation principles: the mass, momentum, and energy conservation equations. With the assumption of one-dimensional flow, these equations, including singlephase and two-phase conservative equations, are introduced in detail as follows.

2.1. Thermal Hydraulic Model Equations. In the natural circulation loop, the calculation of transient thermal hydraulic parameters is solved by the basic conservation equations, including mass conservation equation, momentum conservation equation, and energy conservation equation.

Mass conservation equation:

$$
\frac{\partial \rho}{\partial t}+\frac{1}{A} \frac{\partial W}{\partial z}=0
$$

Momentum conservation equation:

$$
\frac{\partial W}{\partial t}+\frac{\partial}{\partial z}\left(\frac{W^{2}}{\rho A}\right)=-A \frac{\partial p}{\partial z}-\rho g A-\frac{f W^{2}}{2 \rho D_{\mathrm{e}} A} .
$$

Energy conservation equation:

$$
\rho \frac{\partial H}{\partial t}+\frac{W}{A} \frac{\partial H}{\partial z}=\frac{q U_{h}}{A}
$$

2.2. Pressurizer Model. It is very important to accurately simulate the dynamic characteristics of the pressurizer to improve the simulation accuracy of the system. The natural circulation system adopts nitrogen pressurizer. According to the different phases and enthalpies of the fluid in the pressurizer, the pressurizer is divided into two regions, namely, the water region and the nitrogen region. And the following simplification assumptions are given:

(1) The two regions share the same pressure at the same time.

(2) The condensation and evaporation of the water at the interface of the gas-liquid interface are ignored.

(3) The surge water through the surge pipe is well proportioned with the water in the pressurizer.

(4) The same fluid has the same thermodynamic parameters at the same area and time.

The detailed equations of the pressurizer can be found in the published original paper [15]. 


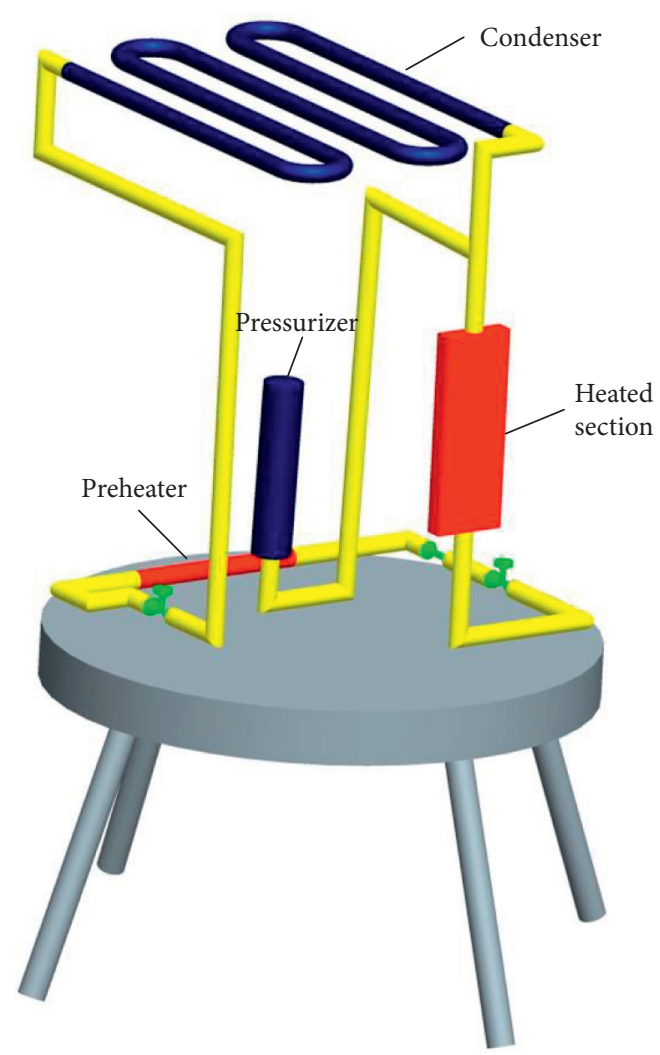

Figure 1: Natural circulation schematic diagram.

2.3. Pipe and Plenum Model. The adiabatic assumption was applied to the pipe and plenums in the natural circulation system. According to the thermal delay model, transient characteristic of coolant enthalpy in pipes and plenums was given as follows:

$$
M \frac{\mathrm{d} h}{\mathrm{~d} t}=W\left(h_{\mathrm{in}}-h\right)
$$

2.4. Ocean Motion Model. A sea-based reactor will be affected by ocean conditions (waves, wind, and tide) in working conditions. The ocean conditions mainly include heeling, heaving, rolling, and pitching motions (shown in Figure 2). Coupled motions, which are coupling of more than one type of ocean condition, are also considered. In heeling motion, there is no additional acceleration or inertial. The forces' effect on the flow is similar to that in steady state, except the gravity. In rolling and pitching motions, only the additional force in flowing direction should be considered. In this paper, it is assumed that the ocean motions are in sinusoidal order:

$$
\theta=\theta_{\mathrm{m}} \sin \left(\frac{2 \pi t}{T}\right)
$$

where $\theta$ is rolling or pithing angle, and $\theta_{\mathrm{m}}$ and $T$ are rolling or pitching amplitude and period, respectively. $t$ is time. Taking derivatives, the angular velocity and angular acceleration for a fluid volume under rolling motion can be written as

$$
\begin{aligned}
& \omega=\frac{2 \pi \theta_{\mathrm{m}}}{T} \cos \left(\frac{2 \pi t}{T}\right), \\
& \beta=-\frac{4 \pi^{2} \theta_{\mathrm{m}}}{T^{2}} \sin \left(\frac{2 \pi t}{T}\right) .
\end{aligned}
$$

The heaving motion is similar to the law of motion.

$$
d=d_{\mathrm{m}} \sin \left(\frac{2 \pi t}{T}\right)
$$

where $d$ is heaving displacement, and $d_{\mathrm{m}}$ and $T$ are heaving amplitude and period, respectively. Taking derivatives, the velocity and acceleration for a fluid volume under heaving motion can be written as

$$
\begin{aligned}
& v=\frac{2 \pi d_{\mathrm{m}}}{T} \cos \left(\frac{2 \pi t}{T}\right), \\
& a=-\frac{4 \pi^{2} d_{\mathrm{m}}}{T^{2}} \sin \left(\frac{2 \pi t}{T}\right) .
\end{aligned}
$$

In the natural circulation system, pipes are three-dimensional. When the system is under rolling motion, the additional force on the fluid in the tube, which is perpendicular to the rolling plane, is omitted.

In the progress of system calculation, the influence of ocean motion means adding additional terms in the momentum equation. According to [16], the momentum equation can be written as follows:

$$
\frac{\partial\left(\rho \mathbf{u}_{\mathrm{r}}\right)}{\partial t}+\frac{\partial\left(\rho \mathbf{u}_{\mathrm{r}} \mathbf{u}_{\mathrm{r}}\right)}{\partial z}=-\frac{\partial p}{\partial z}-\frac{f}{D e} \frac{\rho \mathbf{u}_{\mathrm{r}}^{2}}{2}+(\mathbf{F}+\rho \mathbf{f}) \cdot \mathbf{k},
$$

where $(\mathbf{F}+\rho \mathbf{f}) \cdot \mathbf{k}$ is the part that is influenced by ocean motions including the additional pressure and variant elevation pressure. The ocean motion additional pressure can be expressed as follows:

$$
\mathbf{F}=-\rho\left[\mathbf{a}_{0}+2 \boldsymbol{\omega} \times \mathbf{u}+\boldsymbol{\omega} \times(\boldsymbol{\omega} \times \mathbf{r})+\frac{\mathrm{d} \boldsymbol{\omega}}{\mathrm{d} t} \times \mathbf{r}\right],
$$

where $-2 \omega \times u_{\mathrm{r}}$ is the Coriolis force, $-\omega \times(\omega \times r)$ is the centrifugal force, $-(\mathrm{d} \omega / \mathrm{d} t) \times r$ is the tangential force, and $a_{0}$ is additional acceleration.

2.5. DNB Type CHF Model. For the prediction of DNB type $\mathrm{CHF}$, the calculation model based on the microliquid layer evaporation mechanism is adopted. The model is improved based on the Lee and Mudawar model [17]. The model assumes that, in the near wall area, a small block of steam is formed due to the combination of small bubbles, and the small bubble polymerization increases only the length of the block in the axial direction (Figure 2). There is a very thin layer of liquid between the block and the wall, called the microliquid layer. Boiling crisis occurs when the microliquid layer below is completely depleted due to evaporation during the time the steam is swept:

$$
q_{\mathrm{CHF}}=\frac{\rho_{l} \delta h_{\mathrm{fg}} U_{\mathrm{B}}}{L_{\mathrm{B}}} .
$$

In the above formula, $\delta, U_{\mathrm{B}}$, and $L_{\mathrm{B}}$ represent the distance between the steam block and the heating wall, the 


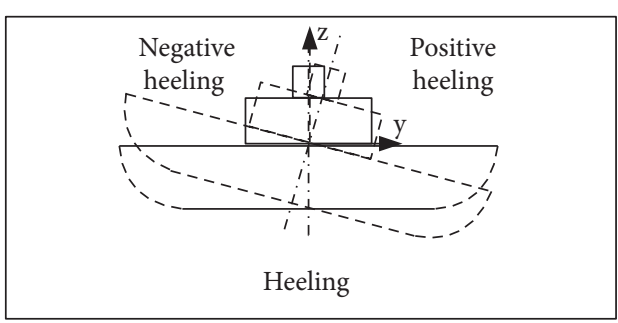

(a)

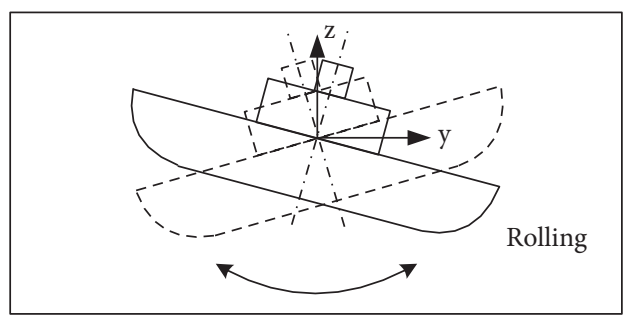

(c)

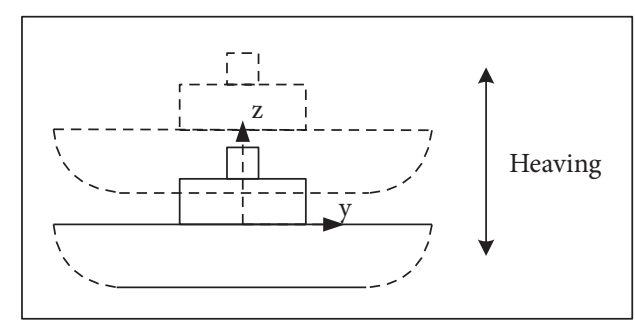

(b)

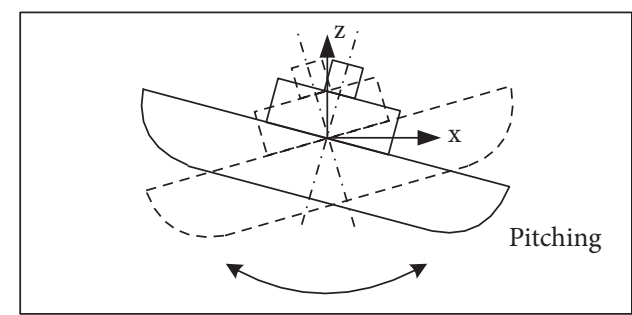

(d)

Figure 2: Schematic of ocean motions. (a) Heeling. (b) Heaving. (c) Rolling. (d) Pitching.

moving speed of the steam block, and the length of the steam block, respectively. Solving these three parameters, we can find the $\mathrm{CHF}$ value $q_{\mathrm{CHF}}$ under the corresponding working conditions.

The computational model of this study still uses the basic idea of the Lee and Mudawar model. $\delta$ and $U_{\mathrm{B}}$ are calculated by the radial and axial force balance of the bubble, while the $L_{\mathrm{B}}$ is calculated by the majority of the microliquid layer model. That is, the Helmholtz wavelength is used. The calculation of $\delta$ and $U_{\mathrm{B}}$ is given below.

The velocity $U_{\mathrm{B}}$ of the steam block in the direction of fluid flow is affected by buoyancy and drag forces in addition to the local liquid phase velocity.

$$
\begin{aligned}
F_{\mathrm{Ba}}+F_{\mathrm{D}} & =0, \\
F_{\mathrm{Ba}} & =\frac{\pi}{4} D_{\mathrm{B}}^{2} L_{\mathrm{B}}\left(\rho_{\mathrm{l}}-\rho_{\mathrm{g}}\right)\left(g \cos (\theta)+a_{\mathrm{a}}(t)\right), \\
F_{\mathrm{D}} & =-\frac{1}{2} \rho_{l} C_{\mathrm{D}}\left(U_{\mathrm{B}}-U_{\mathrm{BL}}\right)^{2} \frac{\pi D_{\mathrm{B}}^{2}}{4},
\end{aligned}
$$

where $F_{\mathrm{Ba}}$ is the buoyancy of the bubble, the unit N. $F_{\mathrm{D}}$ is the drag force of the bubble, the unit N. $\rho_{\mathrm{l}}-\rho_{\mathrm{g}}$ is the difference of vapor-liquid two-phase density, the unit $\mathrm{kg} / \mathrm{m}^{3} . U_{\mathrm{BL}}$ is the liquid velocity of the local radial position of the bubble, the unit $\mathrm{m} / \mathrm{s} . \mathrm{g}$ is the gravitational acceleration, the unit $\mathrm{m} / \mathrm{s}^{2} . \theta$ is the angle of the fluid channel inclination, the unit ${ }^{\circ} . a_{\mathrm{a}}$ is the axial component of the additional acceleration, the unit $\mathrm{m} / \mathrm{s}^{2} . C_{\mathrm{D}}$ is the drag coefficient. From equations (5)-(7), the steam block speed $U_{\mathrm{B}}$ can be solved.

The radial forces experienced by the steam block include the evaporation force $F_{\mathrm{E}}$, the side lift force $F_{\mathrm{L}}$, the wall lubrication force $F_{\mathrm{WL}}$, and the radial buoyancy $F_{\mathrm{Br}}$. The evaporation force is formed by the vapor phase evaporating from the microliquid layer to the steam block. The lifting force is generated by the liquid boundary layer velocity gradient and the relative speed difference between the two phases. The wall lubrication force pushes the bubble near the wall toward the central region.

The reason for radial buoyancy $F_{\mathrm{Br}}$ is that the motion of the fluid channel generates an additional acceleration field, and the additional acceleration field has a component field in the radial direction (vertical to the flow direction). The twophase fluid in the channel flows in this radial acceleration field. The density difference between the two phases causes the bubble to undergo radial buoyancy. The direction of the buoyancy depends on the direction of the additional radial acceleration field and is opposite to it.

The effect of the bubble on the distance from the wall is very small. The force process is shown in Figure 3. The expressions of the various forces are as follows. When the radial force is balanced, the distance $\delta$ between the block and the wall can be determined.

$$
\begin{aligned}
F_{\mathrm{E}}+F_{\mathrm{WL}}+F_{\mathrm{Br}}-F_{\mathrm{L}} & =0, \\
F_{\mathrm{E}} & =\frac{D_{\mathrm{B}} L_{\mathrm{B}} q^{2}}{\left(\rho_{\mathrm{g}} h_{\mathrm{f} g}^{2}\right)}, \\
F_{\mathrm{L}} & =C_{\mathrm{L}} \rho_{\mathrm{l}}\left(U_{\mathrm{B}}-U_{\mathrm{BL}}\right) \frac{\partial U_{L}}{\partial y} \frac{\pi}{4} D_{\mathrm{B}}^{2} L_{\mathrm{B}}, \\
F_{\mathrm{WL}} & =L_{\mathrm{B}} \frac{\pi D_{\mathrm{B}}^{2}}{4} \frac{C_{\mathrm{WL}} \rho_{l}\left(U_{\mathrm{B}}-U_{\mathrm{BL}}\right)^{2}}{D_{\mathrm{B}}}, \\
F_{\mathrm{Br}} & =\left(\rho_{\mathrm{l}, \mathrm{sat}}-\rho_{\mathrm{g}}\right) a_{\mathrm{r}}(t) L_{\mathrm{B}} \frac{\pi D_{\mathrm{B}}^{2}}{4} .
\end{aligned}
$$

In the above formulas, $C_{\mathrm{L}}$ is the lifting force coefficient, $\left(\partial U_{\mathrm{L}}\right) / \partial y$ represents the mainstream velocity gradient of the position of the steam block, which is solved by the Karman velocity equation, and $\mathrm{C}_{\mathrm{WL}}$ is the wall lubrication coefficient. 


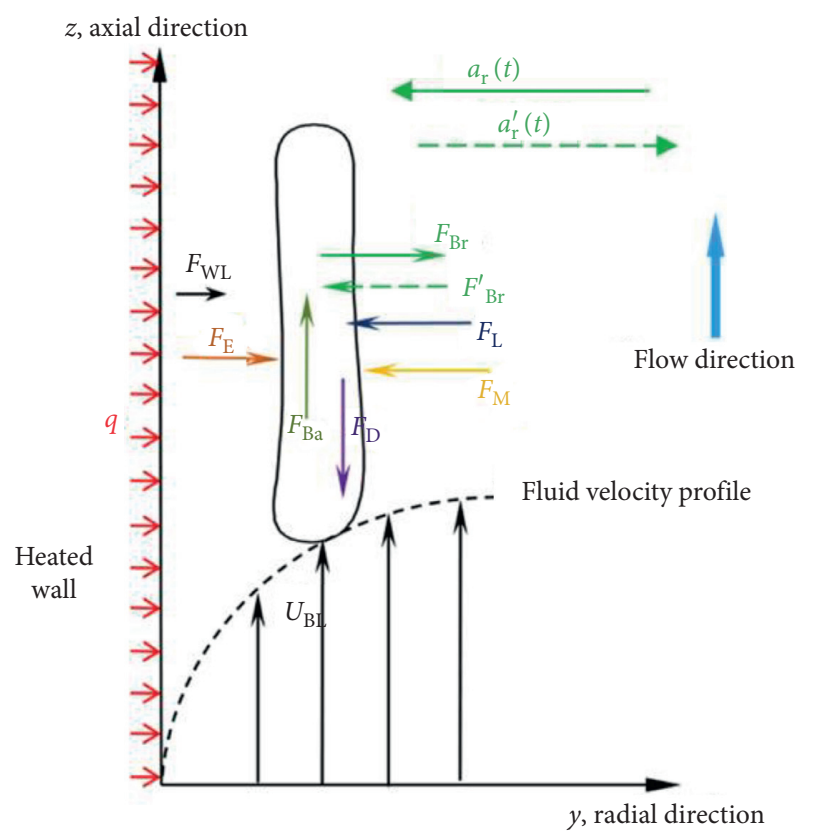

FIGURE 3: Conceptual sketch of liquid sublayer Dryout mechanism.

For the DNB type CHF solution model, other constitutive relations are specifically described in the literature [18].

2.6. Dryout Type CHF Model. In an annular flow regime of narrow rectangular channels, the liquid flows upward adhered to the channel walls forming a continuous annular liquid film. The vapor with entrained droplets flows along the center of the channel and forms a continuous vapor core. Mass is continuously exchanged between the liquid film and droplets entrained in the vapor core in the flow direction: droplets entrained in the vapor core deposit to the liquid film, and the vapor core of high velocity flow cause droplets entrainment in the liquid film.

\subsubsection{Mass Conservation Equations}

(1) The mass conservation equation of the liquid film In the annular region, there exists mass transfer at the liquid film-vapor core interface by the complicated effects on film evaporation, droplets entrainment, and deposition. The mass conservation equation of the liquid film is shown as follows:

$\frac{\partial}{\partial \tau}\left(\rho_{\mathrm{f}} \alpha_{\mathrm{f}}\right)+\frac{\partial\left(\rho_{\mathrm{f}} \alpha_{\mathrm{f}} u_{\mathrm{f}}\right)}{\partial z}=-\frac{q P_{\mathrm{rq}}}{A h_{\mathrm{fg}}}+\frac{P_{\mathrm{rw}} D_{\mathrm{ep}}-\left(P_{\mathrm{rw}} E_{\mathrm{nh}}+P_{\mathrm{rq}} E_{\mathrm{nq}}\right)}{A}$,

where $\rho_{\mathrm{f}}$ is the density of the liquid film, $\alpha_{\mathrm{f}}$ the void fraction of the liquid film, $u_{\mathrm{f}}$ is the average flow velocity of the liquid film, $q$ is the heat flux, $h_{\mathrm{fg}}$ is the latent heat of vaporization, $A$ is the cross-sectional area of rectangular channel, $P_{\mathrm{rw}}$ is the channel periphery, $P_{\mathrm{rq}}$ is the heating periphery, $D_{\mathrm{ep}}$ is the liquid droplets deposition rate, $E_{n h}$ is the liquid droplets entrainment rate caused by breakup of disturbance waves on the liquid film-vapor core interface, and $E_{\mathrm{nq}}$ is the liquid droplets entrainment rate induced by wall heat flux.

(2) The mass conservation equation of droplets

Droplets come from the liquid film evaporation, droplets entrainment, and deposition,

$$
\frac{\partial}{\partial \tau}\left(\rho_{\mathrm{d}} \alpha_{\mathrm{d}}\right)+\frac{\partial\left(\rho_{\mathrm{d}} \alpha_{\mathrm{d}} u_{\mathrm{d}}\right)}{\partial z}=-\frac{P_{\mathrm{rw}} D_{\mathrm{ep}}-\left(P_{\mathrm{rw}} E_{\mathrm{nh}}+P_{\mathrm{rq}} E_{\mathrm{nq}}\right)}{A},
$$

where $\rho_{\mathrm{d}}$ is the density of droplets, $\alpha_{\mathrm{d}}$ is the void fraction of droplets, and $u_{\mathrm{d}}$ is the average flow velocity of droplets.

(3) The mass conservation equation of the vapor core

The vapor core of the annular flow region mainly comes from the liquid film evaporation,

$$
\frac{\partial}{\partial \tau}\left(\rho_{\mathrm{g}} \alpha_{\mathrm{g}}\right)+\frac{\partial\left(\rho_{\mathrm{g}} \alpha_{\mathrm{g}} u_{\mathrm{g}}\right)}{\partial z}=\frac{q P_{\mathrm{rq}}}{A h_{\mathrm{fg}}}
$$

where $\rho_{\mathrm{g}}$ is the density of the vapor core, $\alpha_{\mathrm{g}}$ is the void fraction of the vapor core, and $u_{\mathrm{g}}$ is the average flow velocity of the vapor core.

\subsubsection{Momentum Conservation Equations}

(1) The momentum conservation equation of the liquid film

According to the law of momentum conservation on the liquid film control volume in which frictional force between the liquid film and droplets is ignored, the momentum conservation equation is deduced as follows:

$$
\begin{gathered}
\frac{\partial\left(\rho_{\mathrm{f}} \alpha_{\mathrm{f}} u_{\mathrm{f}}\right)}{\partial \tau}+\frac{\partial\left(\rho_{\mathrm{f}} \alpha_{\mathrm{f}} u_{\mathrm{f}}^{2}\right)}{\partial z}-\frac{D_{\mathrm{ep}} P_{\mathrm{rw}}}{A} u_{\mathrm{d}}+\frac{q P_{\mathrm{rq}}}{A h_{\mathrm{fg}}} u_{\mathrm{f}} \\
+\frac{E_{\mathrm{nh}} P_{\mathrm{rw}}+E_{\mathrm{nq}} P_{\mathrm{rq}}}{A} u_{\mathrm{f}} \\
=-\alpha_{\mathrm{f}} \frac{\partial p}{\partial z}+\alpha_{\mathrm{f}}\left(\mathbf{F}+\rho_{\mathrm{f}} \mathbf{f}\right) \cdot \mathbf{k}-M_{\mathrm{wf}}+M_{\mathrm{fg}},
\end{gathered}
$$

where $M_{\text {wf }}$ is the wall friction, and $M_{\mathrm{fg}}$ is the vaporliquid interface friction.

(2) The momentum conservation equation of droplets The forces of droplets include gravity, pressure, and frictional force between the vapor core and droplets. According to the forces of droplets and momentum exchange between droplets and the liquid film, the momentum conservation equation of droplets is deduced as follows: 


$$
\begin{aligned}
& \frac{\partial\left(\rho_{\mathrm{d}} \alpha_{\mathrm{d}} u_{\mathrm{d}}\right)}{\partial \tau}+\frac{\partial\left(\rho_{\mathrm{d}} \alpha_{\mathrm{d}} u_{\mathrm{d}}^{2}\right)}{\partial z}+\frac{D_{\mathrm{ep}} P_{\mathrm{rw}}}{A} u_{\mathrm{d}}-\frac{E_{\mathrm{nh}} P_{\mathrm{rw}}+E_{\mathrm{nq}} P_{\mathrm{rq}}}{A} u_{\mathrm{f}} \\
& =-\alpha_{\mathrm{d}} \frac{\partial p}{\partial z}+\alpha_{\mathrm{d}}\left(\mathbf{F}+\rho_{\mathrm{d}} \mathbf{f}\right) \cdot \mathbf{k}+M_{\mathrm{gd}},
\end{aligned}
$$

where $M_{\mathrm{gd}}$ is the friction between the vapor core and droplets.

(3) The momentum conservation equation of the vapor core

The forces of the vapor core include gravity, pressure, frictional force between the vapor core and droplets, and frictional force between the vapor core and the liquid film. According to the force of the vapor core and momentum exchange between the vapor core and the liquid film, the momentum conservation equation of the vapor core is deduced as follows:

$$
\begin{array}{r}
\frac{\partial\left(\rho_{\mathrm{g}} \alpha_{\mathrm{g}} u_{\mathrm{g}}\right)}{\partial \tau}+\frac{\partial\left(\rho_{\mathrm{g}} \alpha_{\mathrm{g}} u_{\mathrm{g}}^{2}\right)}{\partial z}-\frac{q P_{\mathrm{rq}}}{A h_{\mathrm{fg}}} u_{\mathrm{f}} \\
=-\alpha_{\mathrm{g}} \frac{\partial p}{\partial z}+\alpha_{\mathrm{g}}\left(\mathbf{F}+\rho_{\mathrm{g}} \mathbf{f}\right) \cdot \mathbf{k}-M_{\mathrm{fg}}-M_{\mathrm{gd}} .
\end{array}
$$

2.6.3. The Energy Conservation Equation. To simplify the three-fluid model, it is assumed that the liquid film, droplets, and the vapor core of annular upward flow are in saturated condition.

For the Dryout type CHF solution model, other constitutive relations are specifically described in the literature [19].

2.7. Auxiliary Model. The correct heat transfer and flow friction factor correlations are key aspects to the code. According to the operation conditions of the natural circulation system, the collier correlation is chosen for laminar heat transfer $(\operatorname{Re}<2000)$, the Sieder-Tate correlation is chosen for the turbulent flow heat transfer ( $\operatorname{Re}>3000)$, and the linear interpolation is applied between the laminar and turbulent correlations for the transition flow heat transfer $(2000 \leq \operatorname{Re} \leq 3000)$. The Jens and Lottes correlation is adopted to calculate the subcooled boiling heat transfer, and the Chen correlation is chosen for saturated boiling heat transfer.

The laminar flow friction factor is calculated by $f=C /$ Re ( $C=64$ for circular tube, $C=96$ for rectangular channel), the turbulent flow friction factor is calculated by Blasius correlation, and the transition flow friction is calculated by linear interpolation. The two-phase frictional multiplier is calculated by Lockhart-Martinelli correlation. The main heat transfer and flow conditions that might occur in the transient process of natural circulation system and corresponding optional correlations are also listed in Tables 1 and 2.
TABLE 1: Flow regimes and heat transfer correlations.

\begin{tabular}{lc}
\hline Flow regime & Correlation \\
\hline Single-phase water: & \\
Laminar flow & Collier correlation \\
Transition flow & Interpolation \\
Turbulent flow & Sieder-Tate correlation \\
\hline Two-phase: & \\
Subcooled boiling & Jens and Lottes correlation \\
Saturated boiling & Chen correlation \\
\hline
\end{tabular}

Quality and void fraction at the onset of annular flow should be given to determine the flow pattern. The typical two-phase flow patterns in a vertical tube are shown in Figure 4. For a uniformly heated channel, the flow patterns contain single-phase flow, subcooled boiling flow, bubbly flow, churn flow, and annular flow. In the present work, the boundary between the subcooled and saturated flow boiling regions is the location where the equilibrium quality equals zero. And the onset of annular flow is the location where the mass quality is evaluated by the widely used Wallis [20] correlation:

$$
x_{\mathrm{ann}}=\frac{0.6+\left(0.4 \sqrt{g \operatorname{De}\left(\rho_{\mathrm{f}}-\rho_{\mathrm{g}}\right) \rho_{\mathrm{f}} / G}\right)}{0.6+\sqrt{\rho_{\mathrm{f}} / \rho_{\mathrm{g}}}} .
$$

2.8. Thermophysical Property Model. The thermophysical properties of water and steam are calculated using the correlations from the international standard IAPWS-IF97.

\section{Code Design and Calculation Procedure}

3.1. Nodalization. To numerically simulate the thermalhydraulic characteristics of natural circulation system according to different geometrical structures and physical boundary conditions, the heated section, preheater, and condenser were divided into different control volumes and junctions, as shown in Figure 5. The node number of the system can be changed according to the calculation requirement.

3.2. Numerical Method. After the nodalization of the natural circulation system, the transient analysis can be obtained to solve a set of ordinary differential equations with initial conditions, which can be summarized as follows:

$$
\begin{aligned}
\frac{\mathrm{d} \vec{y}}{\mathrm{~d} t} & =f\left(t, \vec{y}, \vec{y}^{\prime}\right), \\
\vec{y}\left(t_{0}\right) & =\vec{y}_{0},
\end{aligned}
$$

where $\vec{y}$ is a vector including mass flow rate, enthalpy, and other parameters of each control volumes.

Gear method equipped with Adams predictor-corrector method was adopted for better solution [21]. 
TABLE 2: Flow regimes and flow friction correlations.

\begin{tabular}{lc}
\hline Flow regime & Correlation \\
\hline Single-phase: & $f=\mathrm{C} / \mathrm{Re}(C=64$ for circular tube, $C=96$ for rectangular channel) \\
Laminar flow & Interpolation \\
Transition flow & Blasius model \\
Turbulent flow & \\
\hline Two-phase: & Lockhart-Martinelli model \\
Mixture model (two-phase multiplier) &
\end{tabular}

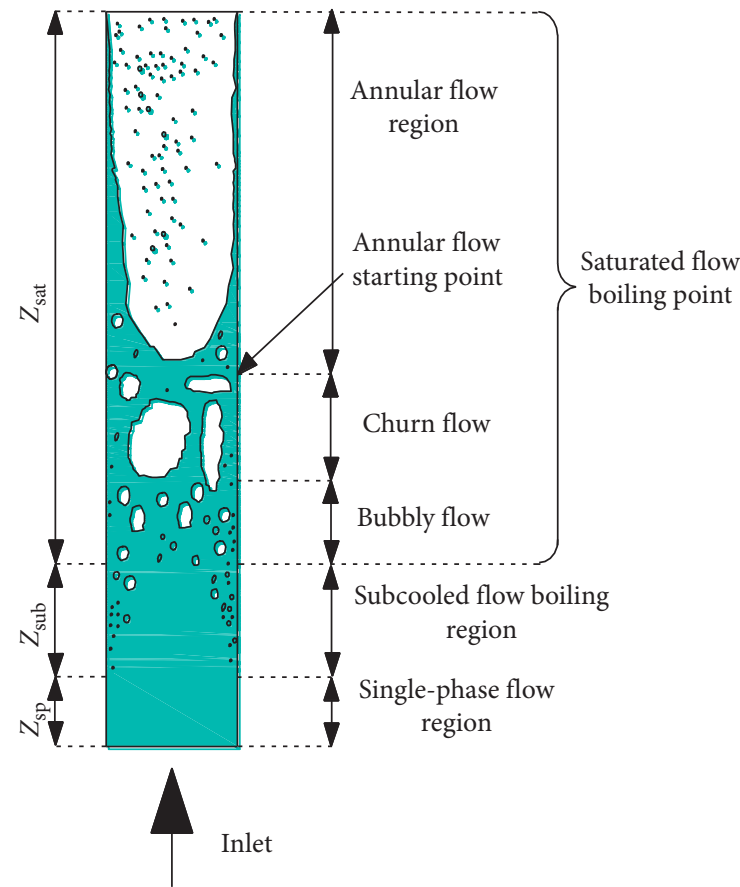

Figure 4: Schematic of flow patterns in a heated vertical tube.

3.3. Code Design. Based on the natural circulation system model and CHF model and numerical methods mentioned above, the code has been developed using FORTRAN 90 language to analyze the CHF characteristics of natural circulation system under ocean conditions. For the purpose of convenient modification and secondary development, modular programming techniques were adopted. The analysis code consists of several functional modules: data input module, initialization module, numerical method module, derivative module, CHF model, and data output module. All the above function modules are called by main program (Figure 6). Furthermore, the initialization module calls the thermophysical property module and the auxiliary model module. The derivative module calculates the right hand of the differential equations and call the thermophysical property module and the auxiliary model module. The flowchart of the code is also given (Figure 7).

3.4. The Calculation Procedure. In this paper, according to the $\mathrm{CHF}$ under natural circulation conditions of ocean conditions, according to the different mechanisms of CHF of DNB and Dryout, the CHF mechanism model of DNB and Dryout is established under the corresponding ocean conditions. The DNB type and Dryout type CHF prediction programs are compiled based on the model. Finally, the DNB type and Dryout type CHF prediction models are coupled with the natural circulation system program by judging the boiling crisis region. In the coupled model, the natural circulation system model is used as the main program framework, and the DNB type and Dryout boiling crisis mechanism models are used as subroutines in the main program framework. The ocean condition module provides boundary conditions for the natural circulation system and boiling crisis calculation. Natural circulation system provides external thermal hydraulic environment boundary for boiling crisis calculation. The boiling crisis feeds back the calculation results to the natural circulation system. The relationship between the models is shown in Figure 8.

The flow of the CHF prediction coupling procedure under natural conditions of ocean conditions is as follows. Figure 7 shows the flowchart of the calculation procedure.

(1) First, the natural circulation system program reads geometric parameters, control parameters, and initialization parameters.

(2) Set an initial heated section heat flux density $q_{\mathrm{m}}$, start steady state calculation, and also adjust the preheating section, condenser parameters, and the resistance coefficient of the valve in the loop to reach the targeted system flow rate, the inlet temperature of heated section.

(3) After the steady state calculation is completed, the steady state result is used as the initial condition to start the transient calculation. The transient calculation obtains the mass quality of the outlet of the heated section for each time step, and the starting point mass quality of the annular flow under the current working condition. By comparing the two mass qualities, we can know whether there is an annular flow in the heated section.

(4) If there is no annular flow in the heated section, the DNB type boiling crisis mechanism model is called for calculation. If annular flow occurs in the heated section, the Dryout type boiling crisis is called to calculate. 


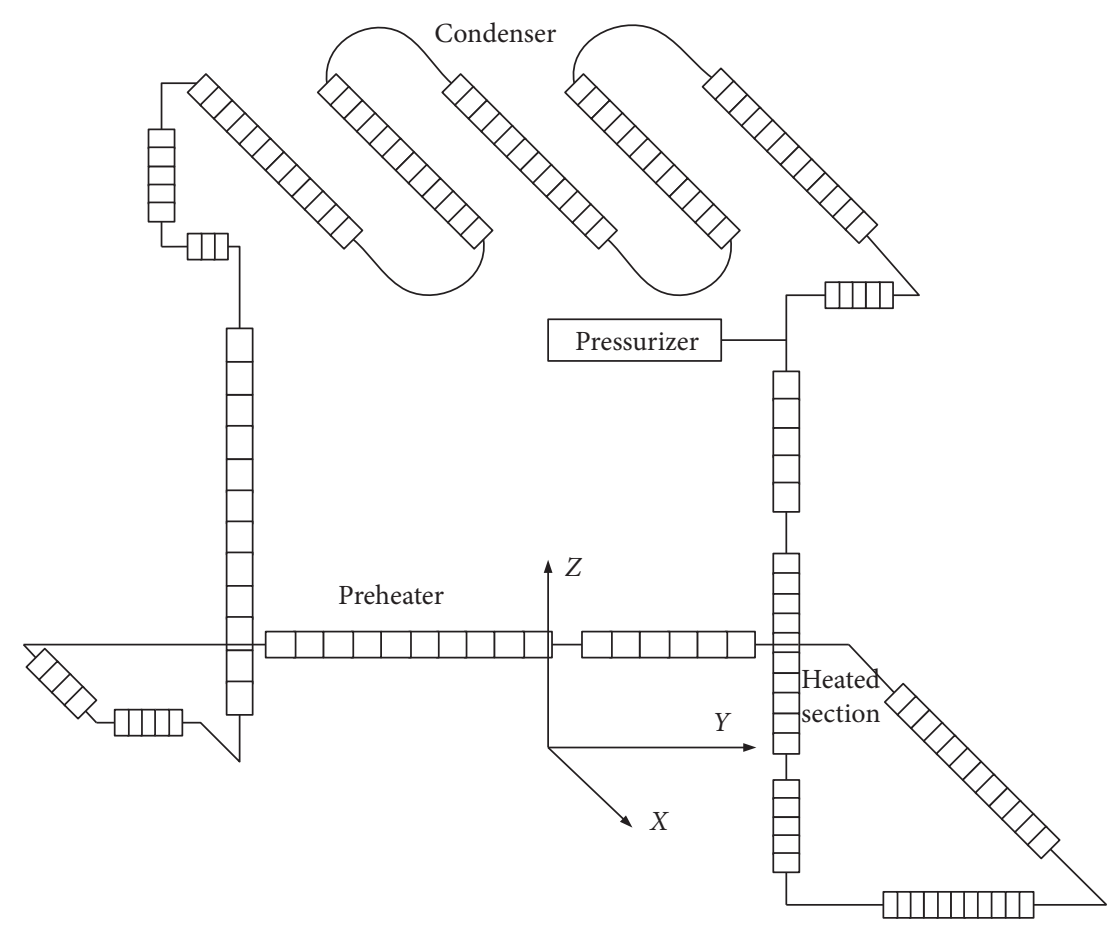

FIGURE 5: Schematic diagram of the nodalization of the system.

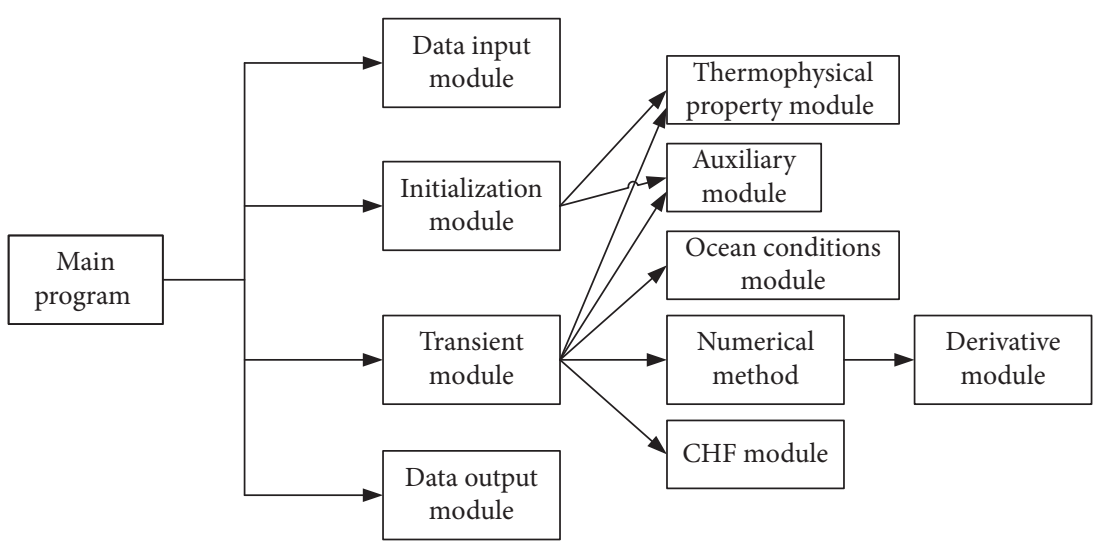

Figure 6: Call relationships of modules.

\section{Model Verification}

To verify the Dryout type CHF model proposed in this paper, the CHF prediction correlation in circular tube proposed by Katto and Ohno [22] is employed. The correlation proposed by Katto is described as follows:

$$
q_{\mathrm{CHF}}=0.234 G h_{\mathrm{fg}}\left(\frac{\rho_{\mathrm{g}}}{\rho_{\mathrm{f}}}\right)^{0.513}\left(\frac{\sigma \rho_{\mathrm{f}}}{G^{2} L}\right)^{0.433} \frac{(L / \mathrm{De})^{0.27}}{1+0.0031 L / \mathrm{De}} .
$$

The CHF values predicted by our model and the correlation are compared in different equivalent diameters, channel lengths, system pressures, and mass flux. The detailed comparison between predicted results and correlation data is shown in Figure 9. It can be seen that the predicted values show good agreement with the Katto correlation.

The verification of the DNB type CHF model can be found in reference [18].

\section{Results and Discussion}

5.1. Influence of Heeling on CHF. Figure 10 is a schematic diagram of the $\mathrm{CHF}$ reduction under heeling condition. The flow characteristic curve of the natural circulation is determined by the loop structure. After the loop is heeled, the height difference between the hot and cold cores is changed, so the flow characteristic curve of the loop also changes. For the natural circulation loop studied in this paper, since the condenser and the heated section are not at a vertical height, the cold and hot core differences of the loop firstly increase 


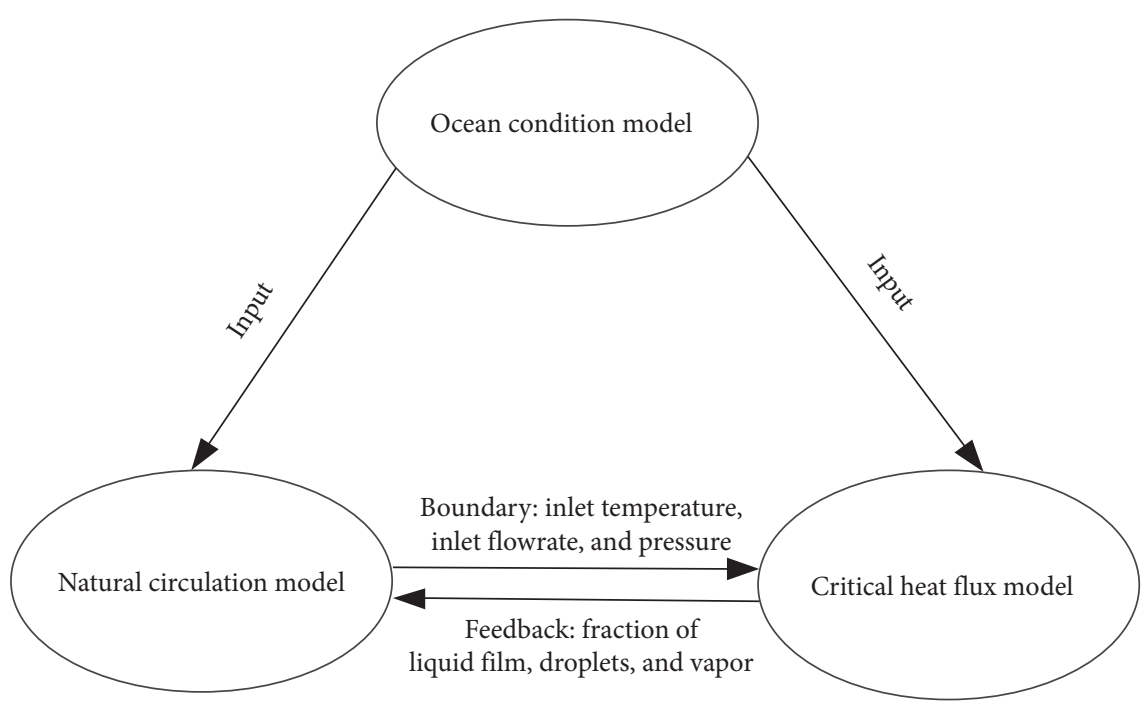

Figure 7: Program flowchart.

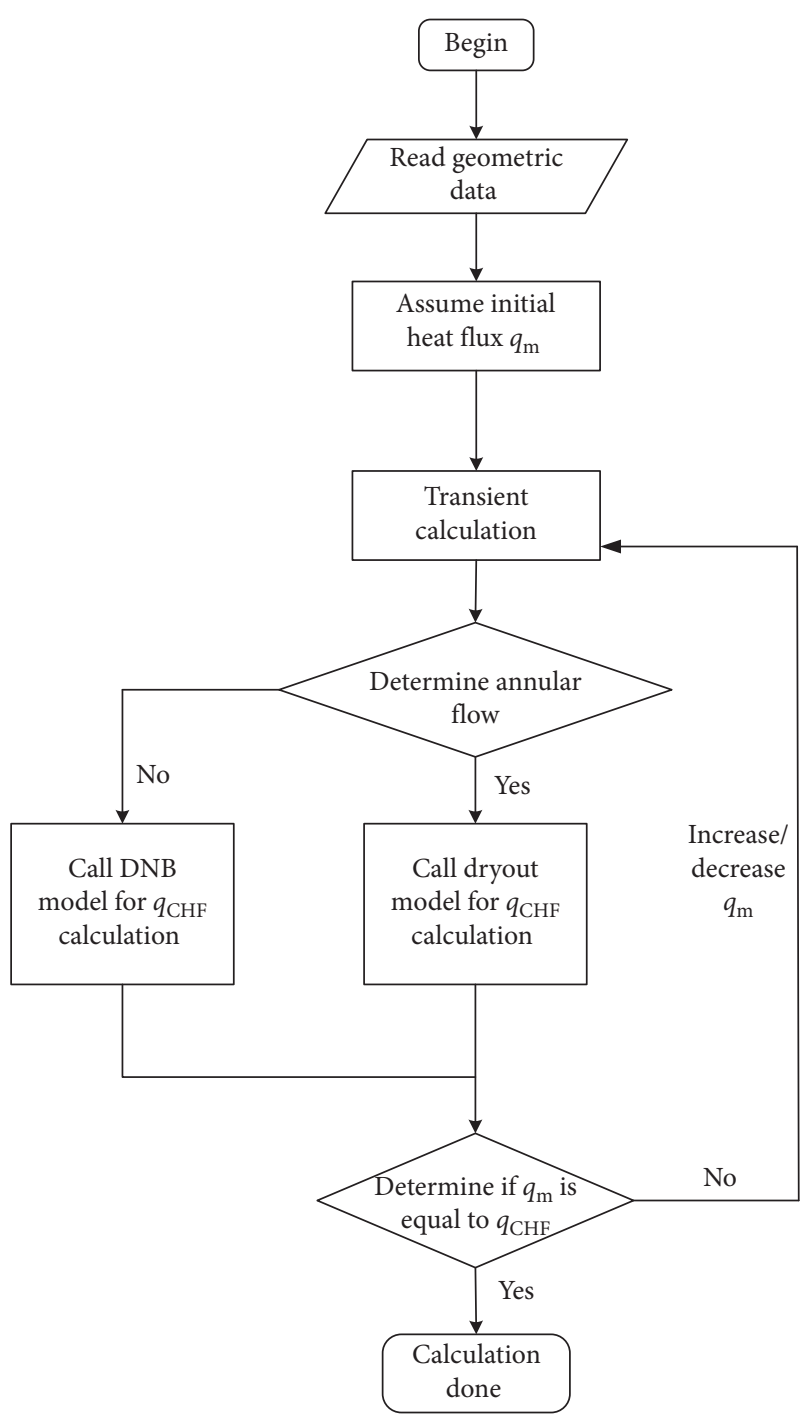

Figure 8: Model coupling diagram. with the positive slope of the loop and begin to decrease after reaching the maximum value, so the system flow rate firstly increases to the maximum and then decreases. As shown in Figure 10, the system mass flow rate reaches maximum value when the inclination angle is $+5^{\circ}$, and the loop flow characteristic curve is the line corresponding to loop heeling $+5^{\circ}$. The loop flow characteristic curve moves below the steady state line when the loop inclines $-5^{\circ}$. For the heated section, the annular liquid film in the rectangular channel in the static state is evenly distributed. With the inclination of the circuit, the flow of the upper and lower liquid films in the channel is redistributed due to the action of gravity, and the upper liquid film thickness will be thinner than the lower liquid film thickness, and the boiling crisis will first occur in the upper pipe wall, so the boiling crisis trend line will move to the left. The difference in the flow rate of the upper and lower liquid film is related to the inclination angle (i.e., the component of gravity along the vertical flow direction) and the fluid flow velocity (i.e., inertial force). In this paper, the distribution of liquid film flow in the upper and lower sides of the channel at the beginning of the annular flow is calculated by the following formula [9].

$$
G_{\mathrm{f}, \mathrm{t}}=\frac{G_{\mathrm{f}}}{2}\left[1-\frac{16}{(2+\mathrm{Fr})^{2}}\right],
$$

where $G_{f, t}$ is the mass flow velocity of the upper side of the channel at the beginning of the annular flow, the unit $\mathrm{kg} \cdot \mathrm{m}^{-2} \cdot \mathrm{s}^{-1}$. Fr is Froude number, calculated by

$$
\operatorname{Fr}=\frac{G}{\left[g \sin \theta \operatorname{De} \rho_{\mathrm{g}}\left(\rho_{\mathrm{f}}-\rho_{\mathrm{g}}\right)\right]^{0.5}} .
$$

5.1.1. Influence of Heeling Angle. Firstly, the variation law of $\mathrm{CHF}$ is analyzed when the whole natural circulation loop is inclined. At this time, the heeling motion not only affects the 


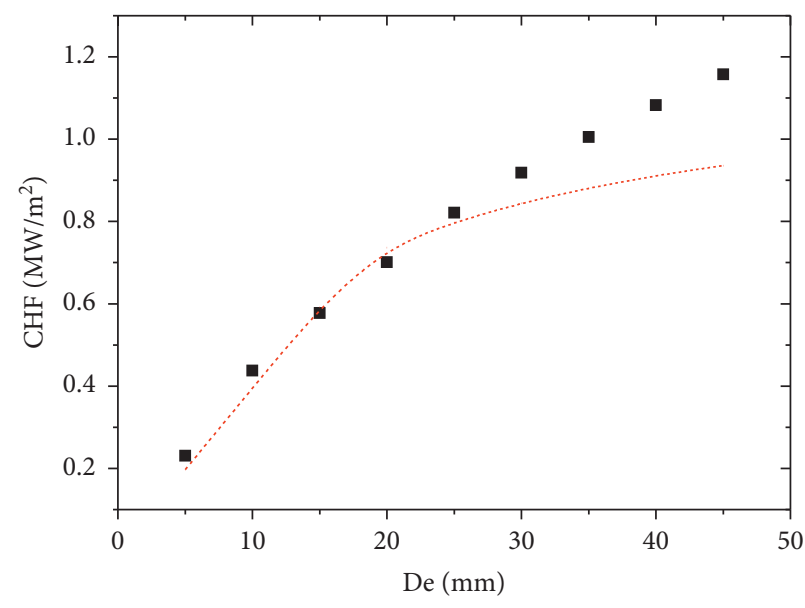

- Predict CHF

..... Katto correlation

(a)

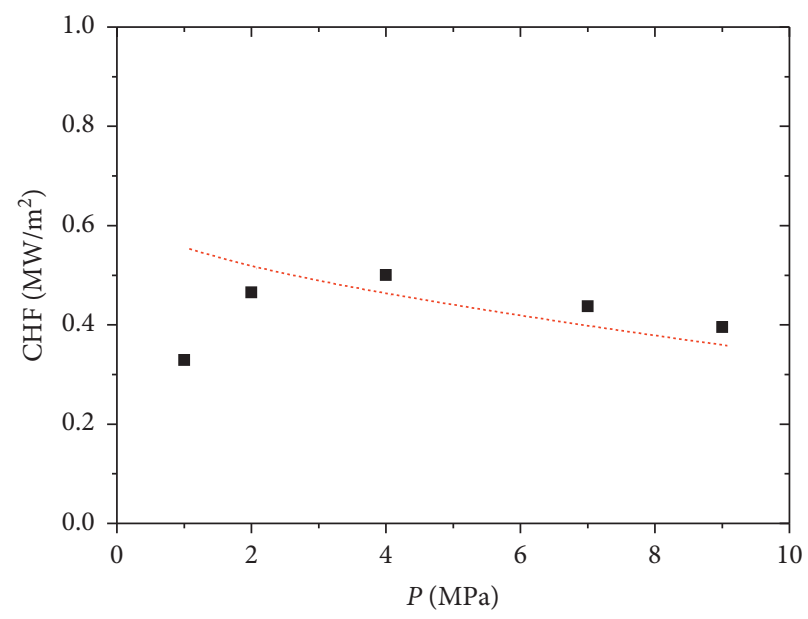

- Predict CHF

..... Katto correlation

(c)

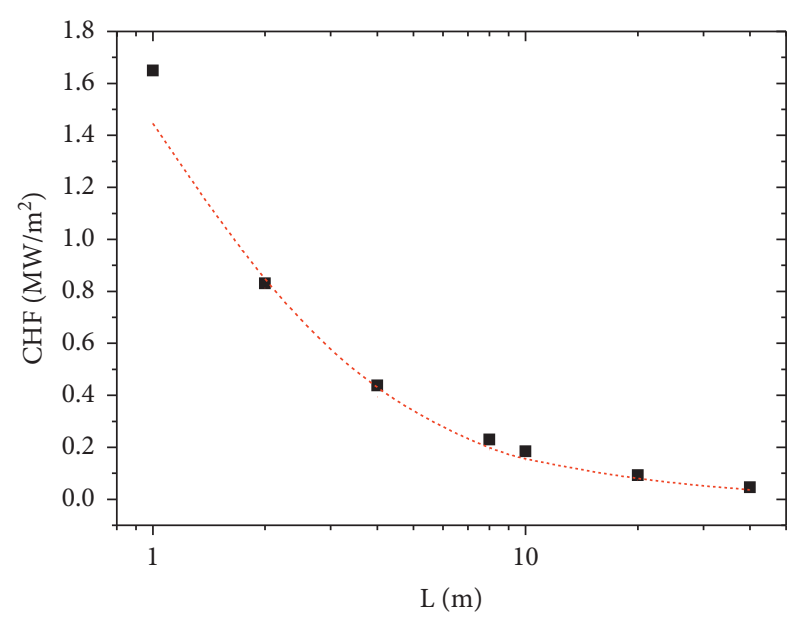

- Predict CHF

..... Katto correlation

(b)

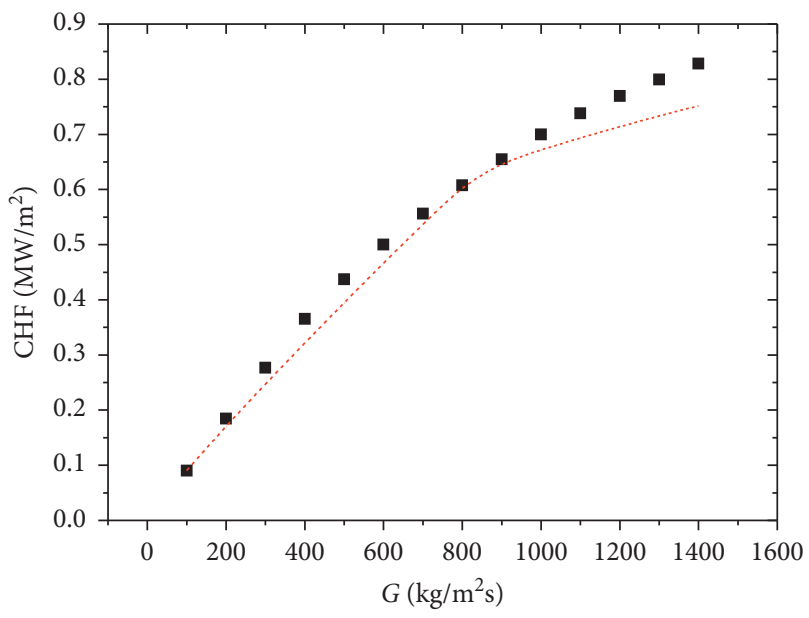

- Predict CHF

... Katto correlation

Figure 9: Comparisons between predicted CHF and Katto correlation. (a) With respect to equivalent diameter. (b) With respect to channel length. (c) With respect to system pressure. (d) With respect to mass flux.

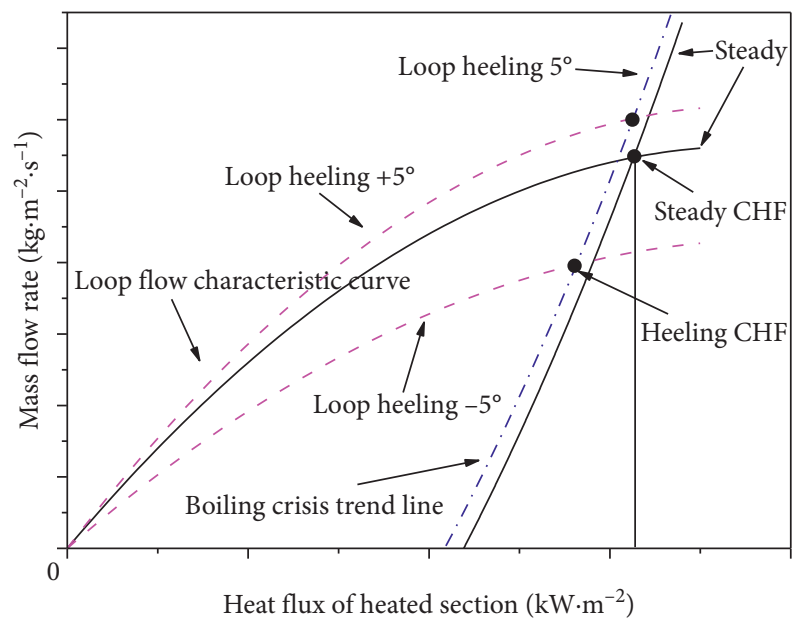

FIGURE 10: Influence of heeling. 


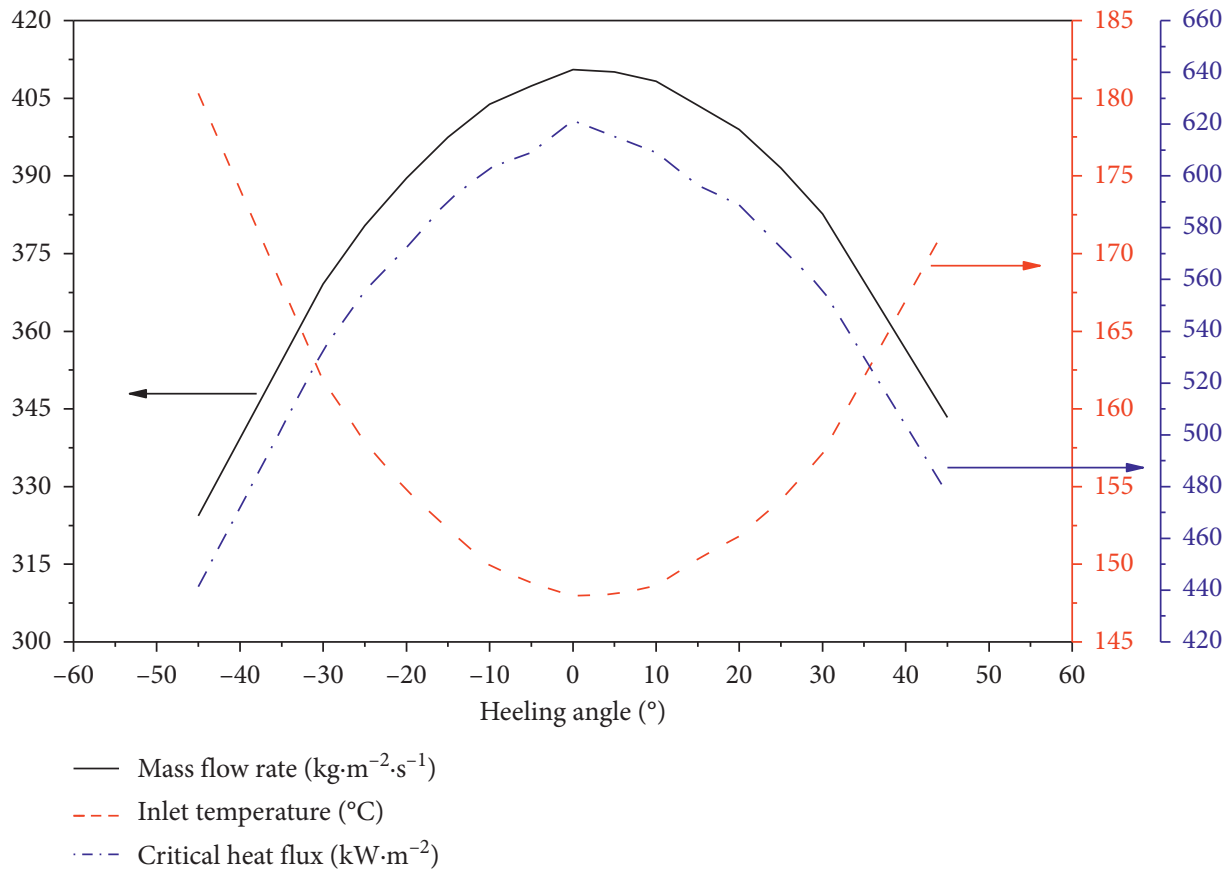

FIgURE 11: Influence of heeling angle on CHF.

thermal hydraulic parameters of the natural circulation system, but also affects the liquid film distribution in the rectangular channel. Figure 11 shows the influence of the inclination angle on CHF. It can be seen from the figure that as the system inclines, the system hot and cold section position difference changes, the loop flow rate changes, and the inlet temperature of the heated section also changes. The inclination causes the distribution of the liquid film uneven. Under the combined action of the two factors, the heat required for the evaporation of the liquid film at the end of the annular flow is reduced. The research object in this paper, shown in Figure 1, is not asymmetric about the axis, so the deviation of system mass flow rate and $\mathrm{CHF}$ around zero degree is asymmetric. CHF decreases as the inclination angle increases from $0^{\circ}$ to $-45^{\circ}$ or $45^{\circ}$ and the maximum decrease of the CHF under heeling condition is $28.89 \%$ when the inclination angle is $-45^{\circ}$.

All in all, the heeling not only changes the thermal hydraulic parameters of the system, but also makes the liquid film thickness distribution in the channel of the heated section uneven. Under the combined influence of the two factors, the CHF of the natural circulation system changes.

5.2. Influence of Heaving Motion on CHF. Figure 12 shows the influence of the heaving condition on the loop flow characteristic curve and the boiling crisis trend line. It can be seen from the figure that the flow rate of the system fluctuates above and below the static value under the conditions of heaving, and the left shift of the critical trend line of the boiling is mainly caused by the change of the pressure in the flow channel caused by the additional force. The pressure change will affect liquid deposition, entrainment, and evaporation of liquid film and result in a decrease in CHF. The intersection of the new boiling crisis trend line and the

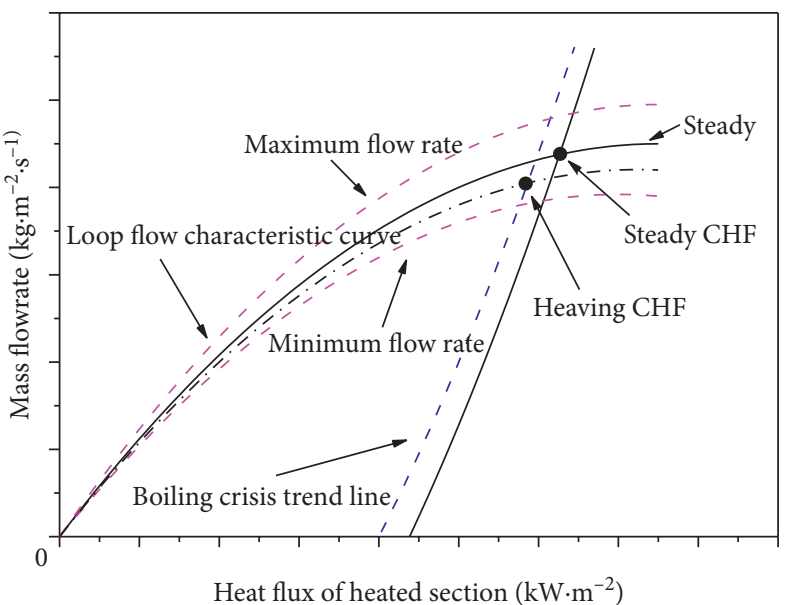

FIGURE 12: Influence of heaving.

new loop flow characteristic curve line is the CHF under heaving condition. When boiling crisis occurs, the system flow rate is between the minimum value and the steady state value. The dotted black line is the loop flow characteristic curve of the system mass flow rate when boiling crisis occurs.

5.2.1. Influence of Heaving Period. Figure 13 shows the variation of the $\mathrm{CHF}$ value of the natural circulation system when the fixed heaving acceleration amplitude is $0.1 \mathrm{~g}$ and $0.3 \mathrm{~g}$. It can be seen that after the amplitude of the heaving acceleration is fixed, when the heaving period is very small (less than $5 \mathrm{~s}$ ), the CHF value increases with the increase of the period. After the period is greater than $10 \mathrm{~s}$, the CHF value tends to be constant with the increase of the heaving period. At this time, the heaving motion not only 


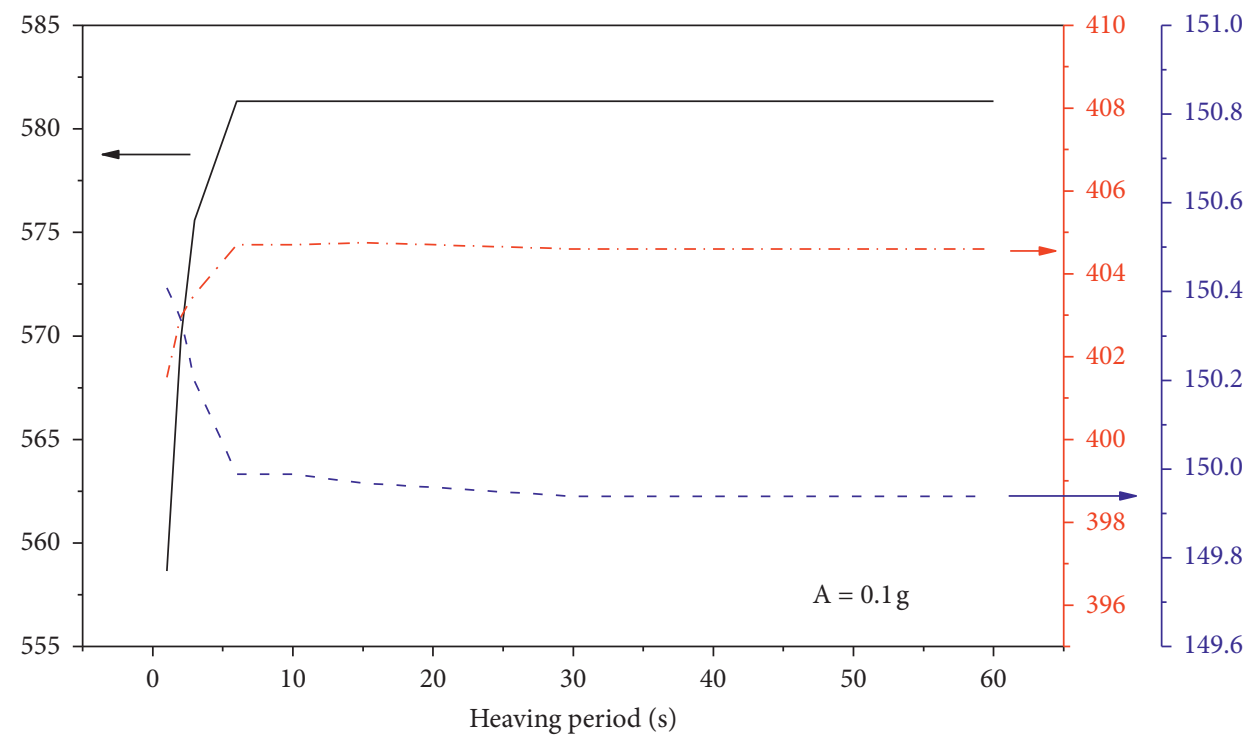

- Critical heat flux $\left(\mathrm{kW} \cdot \mathrm{m}^{-2}\right)$

- . - Mass flow rate $\left(\mathrm{kg} \cdot \mathrm{m}^{-2} \cdot \mathrm{s}^{-1}\right)$

- - - Inlet temperature $\left({ }^{\circ} \mathrm{C}\right)$

(a)

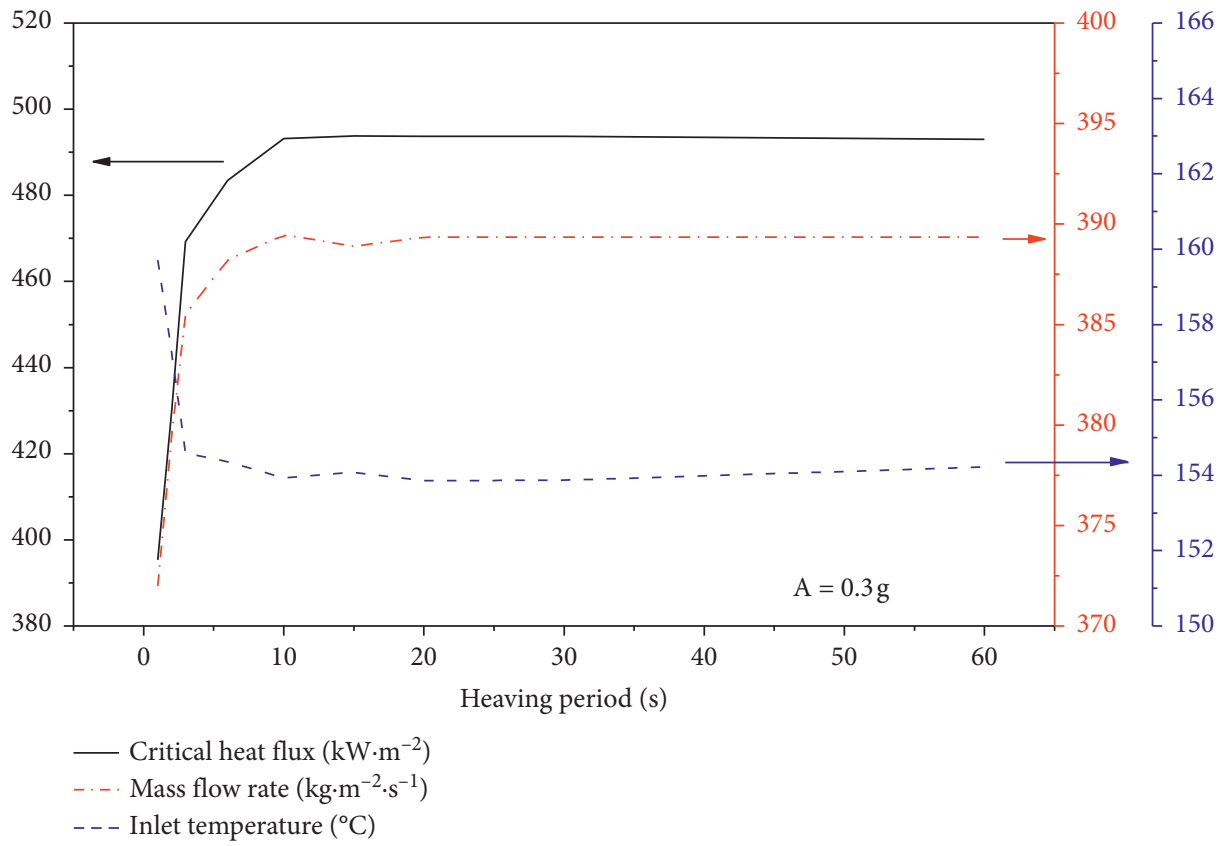

(b)

Figure 13: Influence of heaving period on CHF. (a) $A=0.1 \mathrm{~g}$. (b) $A=0.3 \mathrm{~g}$.

affects the macroscopic thermal hydraulic parameters of the natural circulation system, but also affects the additional force caused by the heaving brings about the pressure change in the heated section, while the pressure affects the deposition, entrainment, and evaporation of the liquid film, and the liquid film will also be axial turbulence, and the CHF will change under the combined effect of the two factors.
When the amplitude of the heaving acceleration is $0.1 \mathrm{~g}$, the maximum increase of the $\mathrm{CHF}$ is $4.06 \%$ when the heaving period is changed. When the heaving acceleration amplitude is $0.3 \mathrm{~g}$, the maximum increase of the CHF is $24.71 \%$ when the heaving period is changed. It shows that the greater the amplitude of the heaving acceleration, the more significant the impact of the heaving period. 


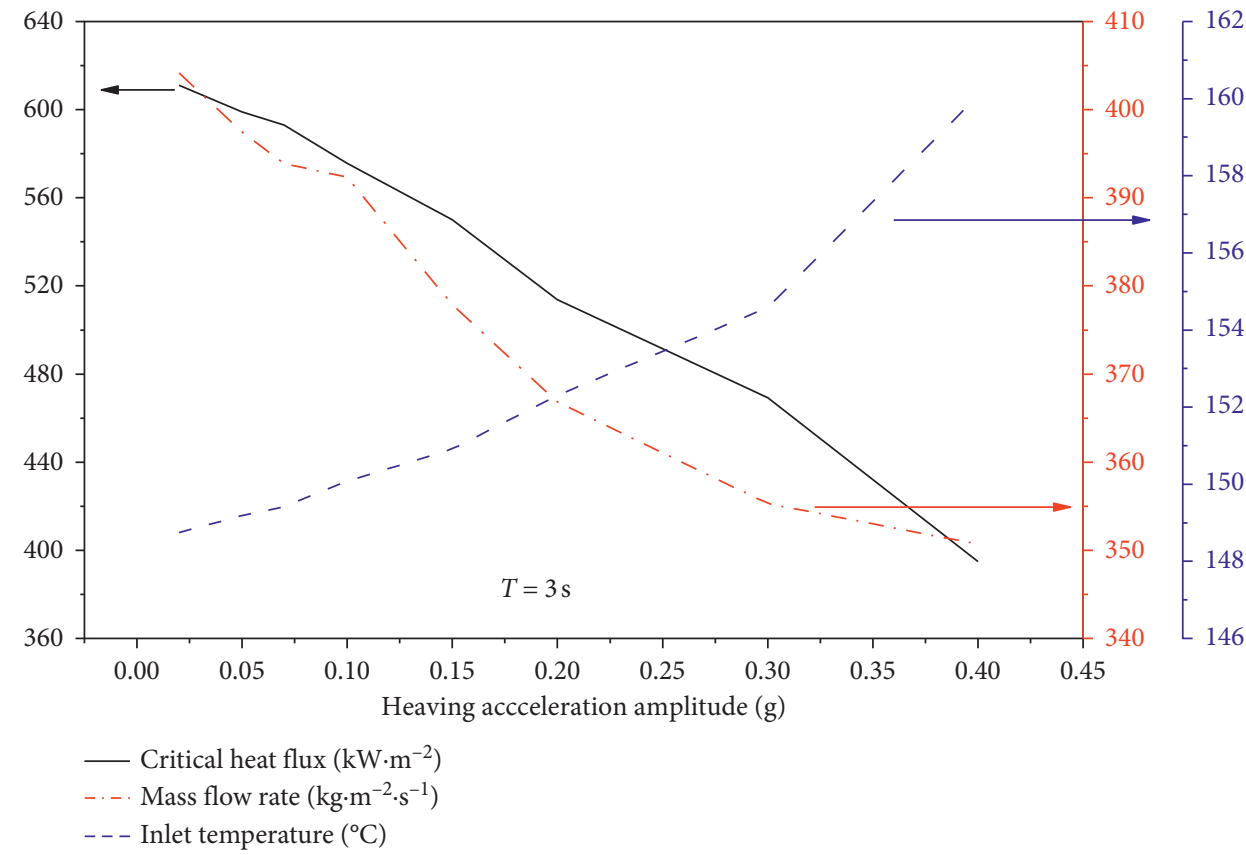

(a)

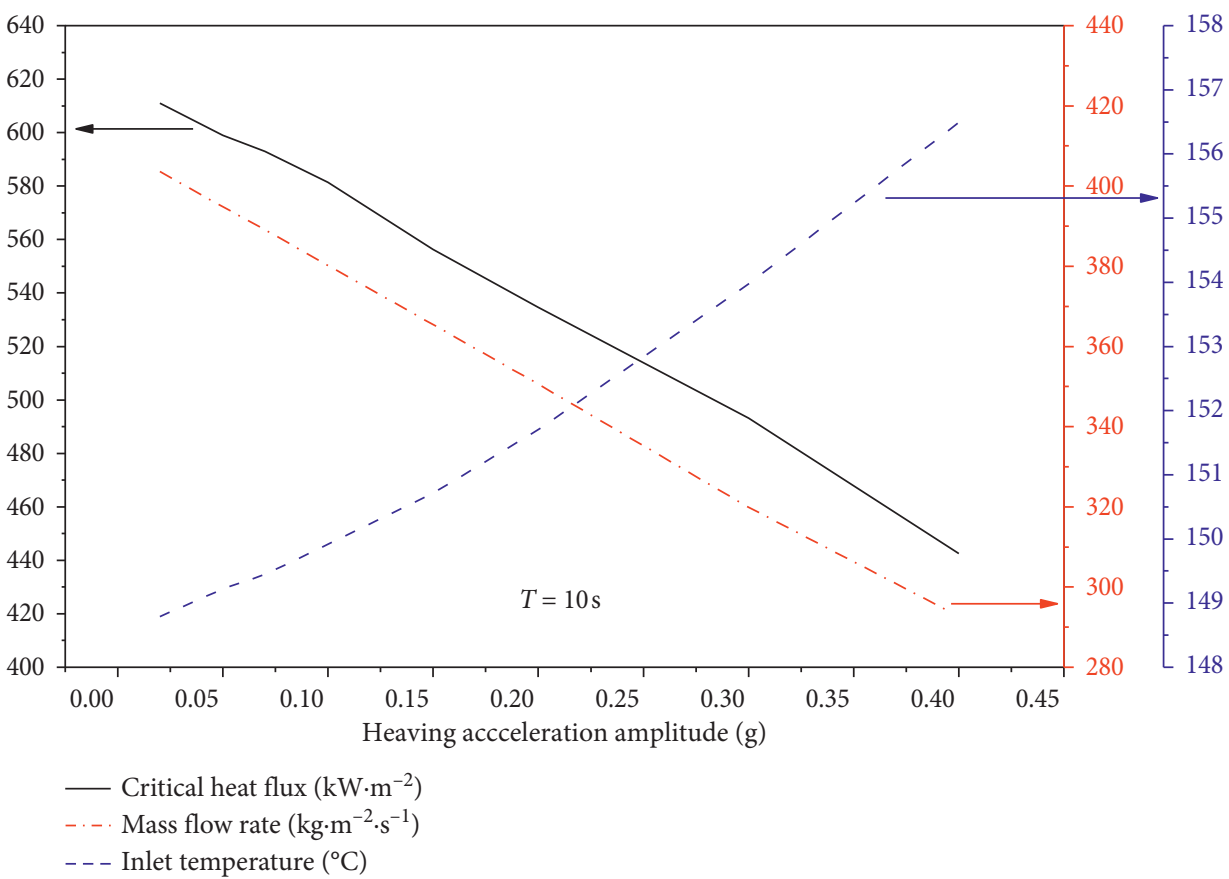

(b)

FIGURE 14: Influence of heaving acceleration amplitude on CHF. (a) $T=3 \mathrm{~s}$. (b) $T=10 \mathrm{~s}$.

5.2.2. Influence of Heaving Acceleration Amplitude. Figure 14 shows the variation of the CHF of the natural circulation system when the fixed heaving period is $3 \mathrm{~s}$ and $10 \mathrm{~s}$. At this time, the heaving motion has an effect on the thermal hydraulic parameters of the natural circulation system and the liquid film distribution in the heated section, that is, the external thermal hydraulic environment at the critical point of boiling changes. It can be seen from the figure that, after the fixed heaving period, as the amplitude of the acceleration increases, the amplitude of the flow fluctuation of the natural circulation system increases, and the system mass flow rate at the critical point of boiling decreases, and the inlet temperature of the heated section increases, so the system $\mathrm{CHF}$ value also gradually decreases.

When the heaving period is $3 \mathrm{~s}$, the maximum $\mathrm{CHF}$ decrease is $35.36 \%$ with the increase of the acceleration amplitude. When the heaving period is $10 \mathrm{~s}$, the maximum $\mathrm{CHF}$ decrease is $27.58 \%$. It indicates that the smaller the heaving period, the more significant the effect of the acceleration amplitude of the heaving. 


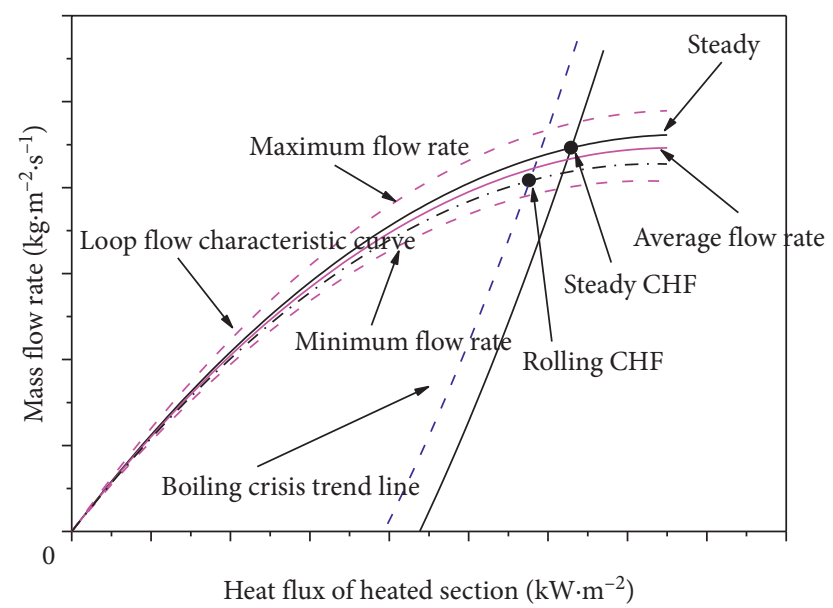

FIgURE 15: Influence of rolling.

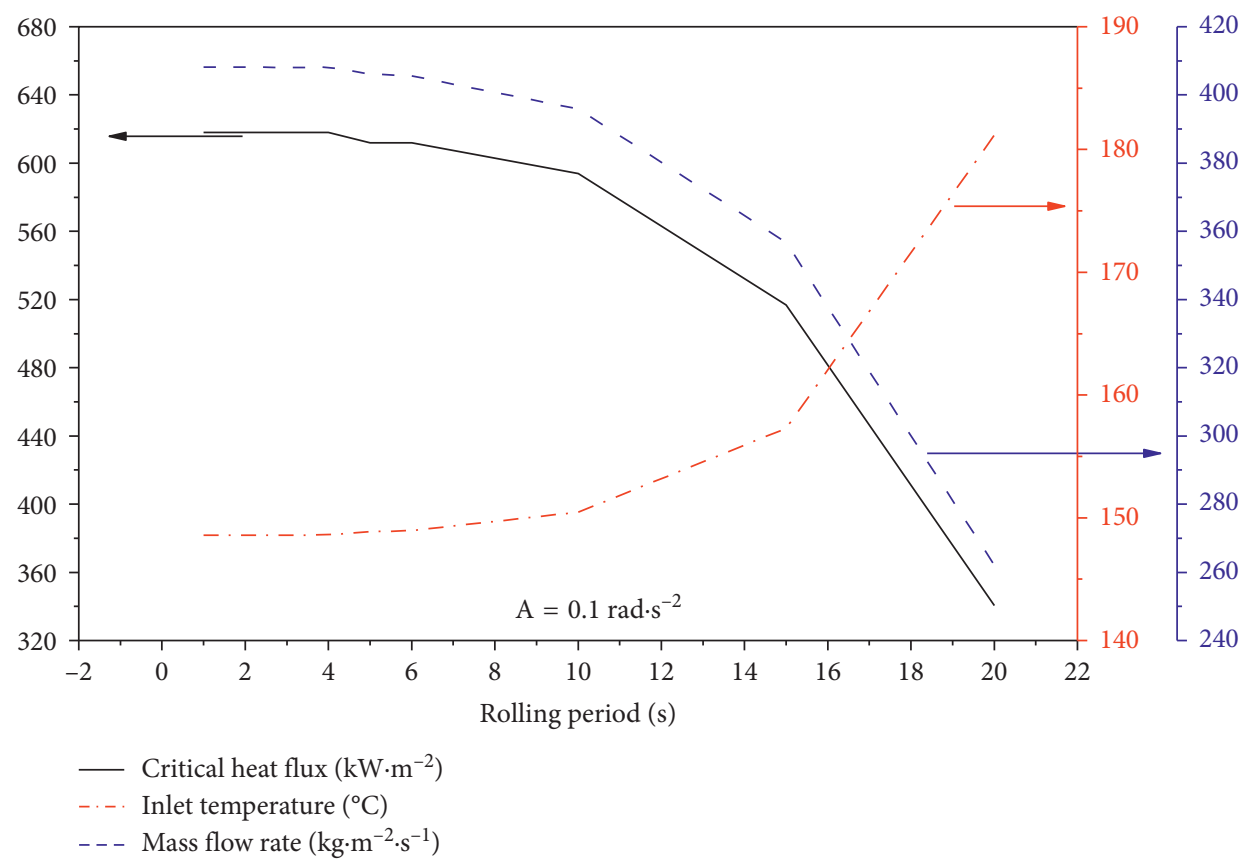

(a)

Figure 16: Continued. 


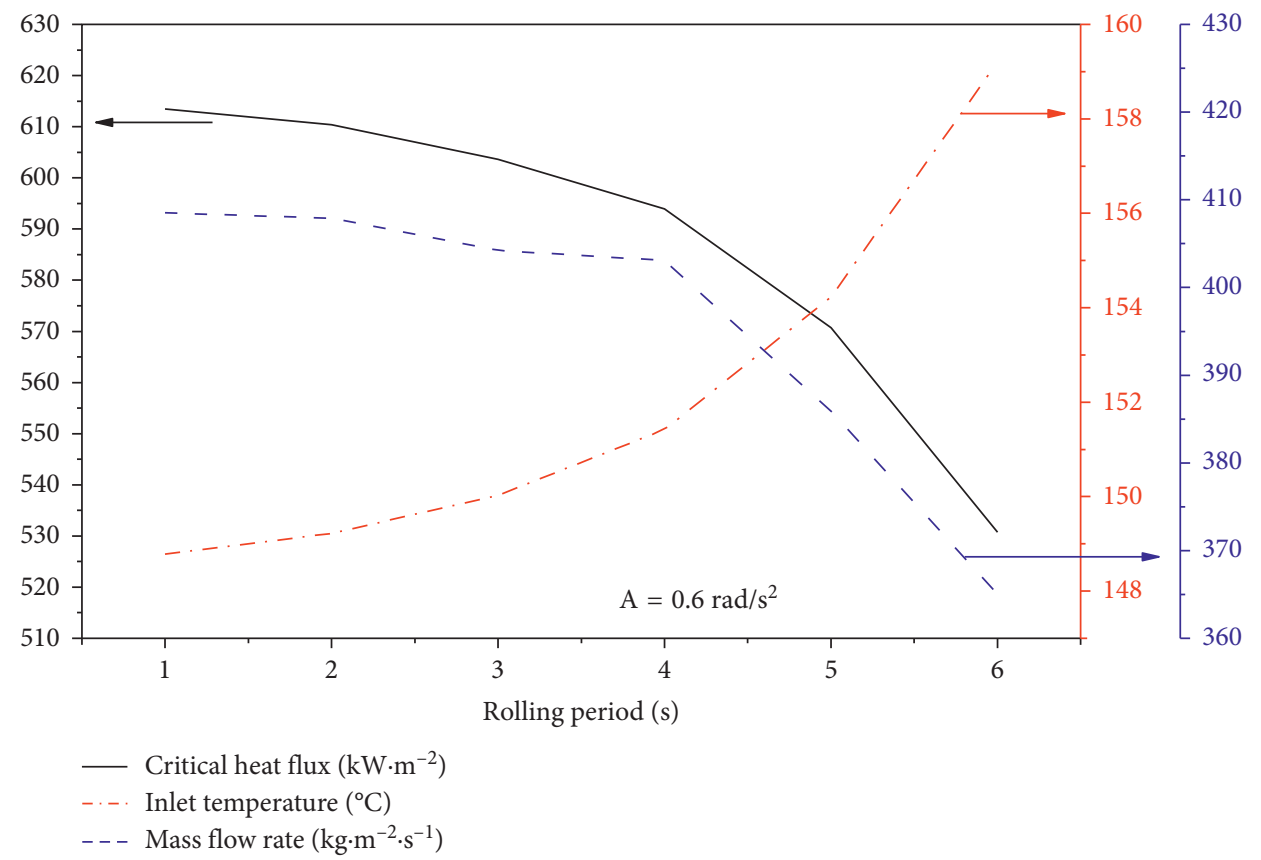

(b)

Figure 16: Influence of rolling period on CHF. (a) $A=0.1 \mathrm{rad} / \mathrm{s}^{2}$. (b) $A=0.6 \mathrm{rad} / \mathrm{s}^{2}$.

5.3. Influence of Rolling Motion on CHF. Figure 15 shows the influence of the rolling condition on the flow characteristic curve of the natural circulation system and the boiling crisis trend line. Since the rolling motion causes the heeling of the loop, and the centripetal drive head and the tangential drive head are simultaneously generated, the average flow rate of the system is reduced. The system flow fluctuates up and down around the average flow rate. The additional pressure drop generated by the rolling motion causes change of the droplet entrainment, deposition rate, and liquid film evaporation rate, and the inclination of the loop causes the distribution of the upper and lower liquid films in the channel to be uneven. Under the joint action of the two factors, the boiling crisis trend line under rolling condition moves to the left of the steady state. When boiling crisis occurs, the system flow rate is between the minimum value and the average value. The dotted black line is the loop flow characteristic curve of the system mass flow rate when boiling crisis occurs.

5.3.1. Influence of Rolling Period. As shown in Figure 16, when the natural circulation loop is rolling, the CHF of the heated section and the inlet temperature of the heated section and system mass flow rate at the critical boiling point are analyzed. It can be seen from the figure that the fixed rolling angular acceleration amplitude is $0.1 \mathrm{rad} \cdot \mathrm{s}^{-2}$ and $0.6 \mathrm{rad} \cdot \mathrm{s}^{-2}$. As the rolling period increases, the rolling angle and angular velocity increase, and the additional pressure drop of the system increases. The fluctuation amplitude of the thermal hydraulic parameters of the system increases. The mass flow rate of the system decreases, and the inlet temperature of the heated section increases when the boiling threshold occurs. The corresponding CHF decreases. When the amplitude of the rolling angle acceleration is $0.1 \mathrm{rad} \cdot \mathrm{s}^{-2}$, the maximum decrease of the $\mathrm{CHF}$ is $44.9 \%$ with the increase of the rolling period. When the amplitude of the rolling angle acceleration is $0.6 \mathrm{rad} \cdot \mathrm{s}^{-2}$, the maximum reduction in $\mathrm{CHF}$ is $13.5 \%$ with the increase of the rolling period.

5.3.2. Influence of Rolling Angle Acceleration Amplitude. Figure 17 shows the influence of the rolling angle acceleration on the CHF and the thermal parameters of the boiling crisis point system with a fixed rolling period of $4.5 \mathrm{~s}$. It can be seen from the figure that as the amplitude of the acceleration of the rolling angle increases, the additional pressure drop caused by the rolling affects the thermal hydraulic parameters of the system. From the previous analysis, the fluctuation of the system flow rate increases with the increase of the rolling angle acceleration. The mass flow rate at the critical point of boiling decreases. The inlet temperature of the heated section increases. On the other hand, with the increase of acceleration of the rolling angle, the influence on the liquid film at the exit of the heated section increases. Under the combined influence of the two factors, the $\mathrm{CHF}$ reduces. When the rolling period is $4.5 \mathrm{~s}$, the maximum decrease in $\mathrm{CHF}$ is $8.5 \%$ with the increase of the amplitude of the rolling angle acceleration.

5.3.3. Influence of Rolling Angle Amplitude. Figure 18 shows the influence of the rolling angle amplitude on the system parameters of boiling crisis point and CHF. It can be seen 


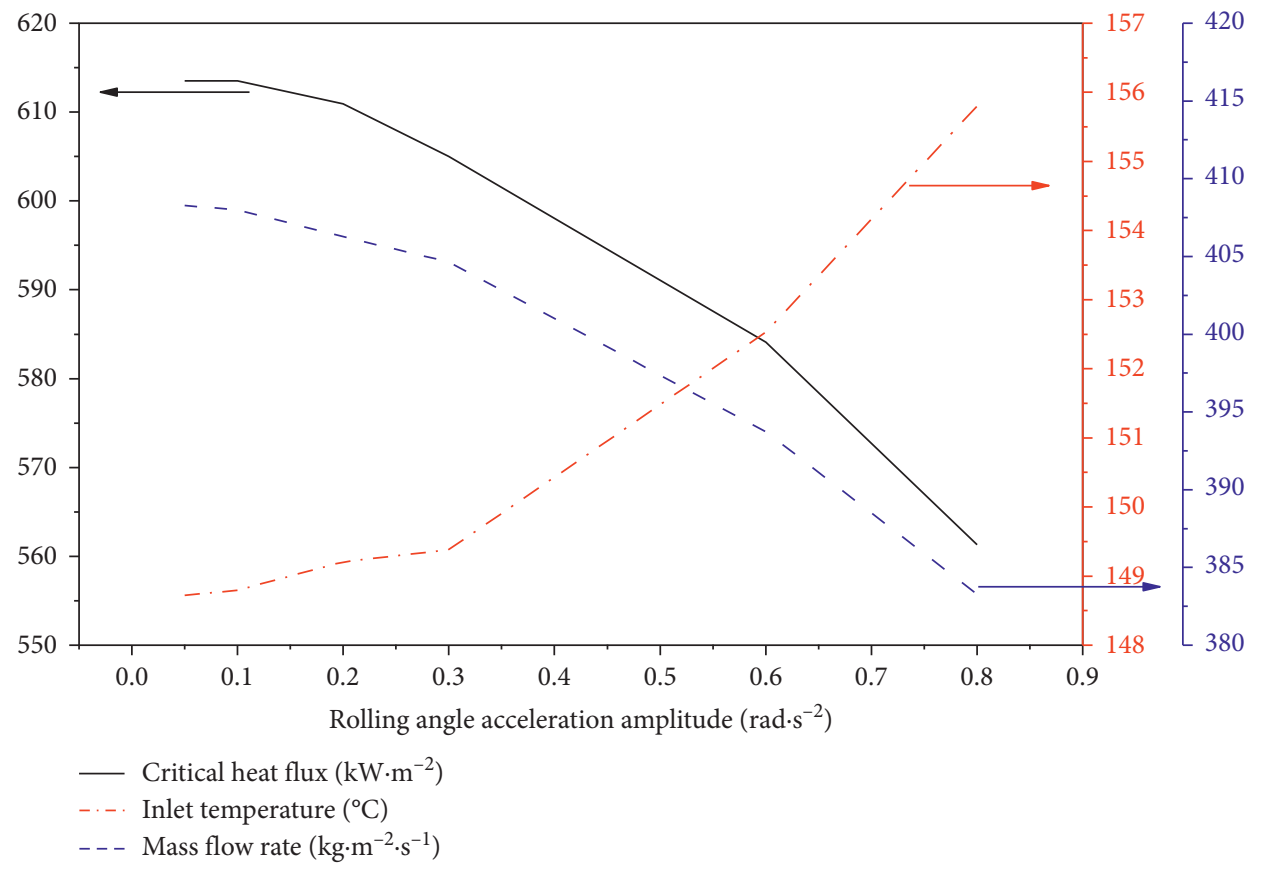

Figure 17: Influence of rolling angle acceleration amplitude on CHF, $T=4.5 \mathrm{~s}$.

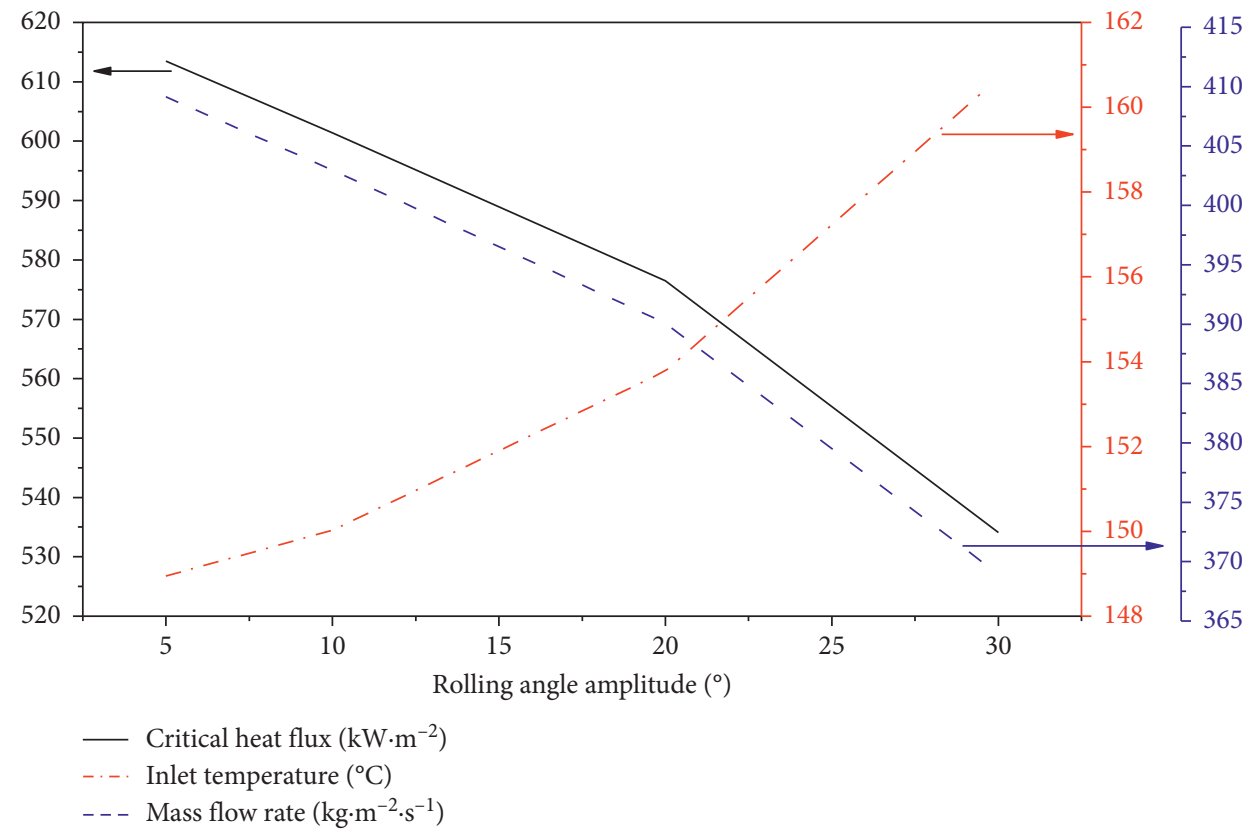

Figure 18: Influence of rolling angle amplitude on $\mathrm{CHF}, T=4.5 \mathrm{~s}$.

that as the amplitude of the rolling angle increases, the additional pressure drop of the system increases, the amplitude of the system fluctuations such as the flow rate increases, and the influence on the liquid film is enhanced. As the rolling angle increases, the mass flow rate at the boiling crisis point decreases, the inlet temperature increases, and the CHF decreases. When the rolling period is $4.5 \mathrm{~s}$, the maximum CHF decrease is $12.95 \%$ as the amplitude of the rolling angle increases.

\section{Conclusion}

In this paper, a series of theoretical models including CHF mechanistic models and natural circulation system model have been developed, and the CHF in the rectangular channel of natural circulation system under ocean conditions is studied. The prediction model of DNB and Dryout boiling crisis under ocean conditions, the thermal hydraulic characteristics analysis model of natural circulation system, and the theoretical model 
of additional force of ocean conditions are established. The corresponding calculation program was developed through multimodel and cross-dimensional coupling, and the $\mathrm{CHF}$ characteristics of natural circulation under ocean conditions were studied. Within the scope of the study parameters, the influence of ocean conditions on the $\mathrm{CHF}$ is great, and the maximum degradation of $\mathrm{CHF}$ is about $45 \%$.

\section{Nomenclature}

$a_{0}: \quad$ Additional acceleration $\left(\mathrm{m} / \mathrm{s}^{2}\right)$

A: $\quad$ Flow area $\left(\mathrm{m}^{2}\right)$

$C_{\mathrm{D}}$ : Drag coefficient

$C_{\mathrm{L}}$ : Lifting force coefficient

$\mathrm{C}_{\mathrm{WL}}$ : Wall lubrication coefficient

De: Hydraulic equivalent diameter of the flow channel (m)

$D_{\text {ep }}$ : Liquid droplets deposition rate $\left(\mathrm{kg} / \mathrm{m}^{2} \cdot \mathrm{s}^{1}\right)$

$d$ : Heaving displacement $(\mathrm{m})$

$d_{\mathrm{m}}$ : Heaving amplitude $(\mathrm{m})$

$E_{\text {nh: }}$ Liquid droplets entrainment rate caused by breakup of disturbance waves on the liquid film-vapor core interface $\left(\mathrm{kg} / \mathrm{m}^{2} \cdot \mathrm{s}^{1}\right)$

$E_{\text {nq: }}$ Liquid droplets entrainment rate induced by wall heat flux $\left(\mathrm{kg} / \mathrm{m}^{2} \cdot \mathrm{s}^{1}\right)$

F: $\quad$ Ocean motion additional pressure $(\mathrm{Pa})$

$F_{\mathrm{B}}$ : $\quad$ Buoyancy of the bubble $(\mathrm{N})$

$F_{\mathrm{D}}$ : $\quad$ Drag force of the bubble $(\mathrm{N})$

f: $\quad$ Friction coefficient

$g$ : Gravitational acceleration $\left(\mathrm{m} / \mathrm{s}^{2}\right)$

$G_{f, t}$ : Mass flow velocity of the upper side of the channel at the beginning of the annular flow $\left(\mathrm{kg} / \mathrm{m}^{2} \cdot \mathrm{s}^{1}\right)$

$h_{\mathrm{fg}}$ : Latent heat of vaporization $(\mathrm{J} / \mathrm{kg})$

$H$ : $\quad$ Specific enthalpy $(\mathrm{J} / \mathrm{kg})$

$K$ : Local resistance factor

$L$ : Flow length (m)

$L_{\mathrm{B}}$ : $\quad$ Length of the steam block $(\mathrm{m})$

$M$ : $\quad$ Fluid mass of the control volume $(\mathrm{kg})$

$M_{\text {wf: }}$ Wall friction $\left(\mathrm{N} / \mathrm{m}^{3}\right)$

$M_{\mathrm{fg}}$ : Vapor-liquid interface friction $\left(\mathrm{N} / \mathrm{m}^{3}\right)$

$M_{\mathrm{gd}}$ : Friction between the vapor core and droplets $\left(\mathrm{N} / \mathrm{m}^{3}\right)$

$p: \quad$ Pressure $(\mathrm{Pa})$

$\Delta p_{\mathrm{f}}: \quad$ Friction pressure drop $(\mathrm{Pa})$

$\Delta p_{\mathrm{c}}$ : Local pressure drop $(\mathrm{Pa})$

$\Delta p_{\mathrm{el}}$ : Elevation pressure drop $(\mathrm{Pa})$

$P_{\mathrm{rw}}$ : Channel periphery $(\mathrm{m})$

$P_{\mathrm{rq}}$ : Heating periphery $(\mathrm{m})$

$q$ : Heat flux $\left(\mathrm{W} / \mathrm{m}^{2}\right)$

$r$ : Position vector $(\mathrm{m})$

T: $\quad$ Motion period (s)

$t$ : Time (s)

$u$ : Average flow velocity $(\mathrm{m} / \mathrm{s})$

$U_{\mathrm{h}}: \quad$ Heating perimeter $(\mathrm{m})$

$U_{\mathrm{B}}$ : Moving speed of the steam block $(\mathrm{m} / \mathrm{s})$

$U_{\mathrm{BL}}$ : Liquid velocity of the local radial position of the bubble $(\mathrm{m} / \mathrm{s})$

$W: \quad$ Mass flow rate $(\mathrm{kg} / \mathrm{s})$

$x_{\text {ann }}$ : Mass quality of onset of annular flow
Greek symbols

$\rho: \quad$ Density $\left(\mathrm{kg} / \mathrm{m}^{3}\right)$

$\theta$ : $\quad$ Rolling or pithing angle (rad)

$\theta_{\mathrm{m}}$ : Rolling or pitching amplitude (rad)

$\omega$ : Rolling or pitching angular velocity ( $\mathrm{rad} / \mathrm{s})$

$\beta$ : Rolling or pitching angular acceleration $\left(\mathrm{rad} / \mathrm{s}^{2}\right)$

$\alpha$ : Void fraction

$\delta$ : Distance between the steam block and the heating wall (m)

Subscripts

1: Liquid

g: Vapor

f: Liquid film

d: Droplets.

\section{Data Availability}

The data used in the paper to support the findings of this study are available from the corresponding author upon request.

\section{Conflicts of Interest}

The authors declare that there are no conflicts of interest regarding the publication of this paper.

\section{Acknowledgments}

The authors would like to acknowledge the support of Nuclear Power Institute of China.

\section{References}

[1] N. Isshiki, "Effects of heaving and listing upon thermo-hydraulic performance and critical heat flux of water-cooled marine reactors," Nuclear Engineering and Design, vol. 4, no. 2, pp. 138-162, 1966.

[2] T. Otsuji and A. Kurosawa, "Critical heat flux of forced convection boiling in an oscillating acceleration field - I. General trends," Nuclear Engineering and Design, vol. 71, no. 1, pp. 15-26, 1982.

[3] T. Otsuji and A. Kurosawa, "Critical heat flux of forced convection boiling in an oscillating acceleration field-II. Contribution of flow oscillation," Nuclear Engineering and Design, vol. 76, no. 1, pp. 13-21, 1983.

[4] T. Otsuji and A. Kurosawa, "Critical heat flux of forced convection boiling in an oscillating acceleration field-III. Reduction mechanism of CHF in subcooled flow boiling," Nuclear Engineering and Design, vol. 79, no. 1, pp. 19-30, 1984.

[5] S. Wang, B.-W. Yang, Z. Zhou, and J. Long, "Review on thermal-hydraulic characteristics of nuclear reactors under ocean conditions," Nuclear Science and Engineering, vol. 193, no. 1-2, pp. 14-32, 2018.

[6] D. X. Du, W. X. Tian, G. H. Su, S. Z. Qiu, Y. P. Huang, and $\mathrm{X}$. Yan, "Theoretical study on the characteristics of critical heat flux in vertical narrow rectangular channels," Applied Thermal Engineering, vol. 36, no. 2012, pp. 21-31, 2012.

[7] F. Pu, Q. Suizheng, and J. Dounan, "An investigation of flow characteristics and critical heat flux in vertical upward round tube," Nuclear Science and Techniques, vol. 17, no. 3, pp. 170-176, 2006. 
[8] J. Huang, Y. Huang, Q. Wang, and B. Bai, "Numerical study on effect of gap width of narrow rectangular channel on critical heat flux enhancement," Nuclear Engineering and Design, vol. 239, no. 2, pp. 320-326, 2009.

[9] T. Okawa, A. Kotani, I. Kataoka, and M. Naitoh, "Prediction of the critical heat flux in annular regime in various vertical channels," Nuclear Engineering and Design, vol. 229, no. 2-3, pp. 223-236, 2004.

[10] G. Su, J. Gou, S. Qiu, X. Yang, and D. Jia, "Theoretical calculation of annular upward flow in a narrow annuli with bilateral heating," Nuclear Engineering and Design, vol. 225, no. 2-3, pp. 219-247, 2003.

[11] H. Umekawa, M. Ozawa, A. Miyazaki, K. Mishima, and T. Hibiki, "Dryout in a boiling channel under oscillatory flow condition," JSME International Journal Series B, vol. 39, no. 2, pp. 412-418, 1996.

[12] W. Geping, Q. Suizheng, S. Guanghui, T. Wenxi, and J. Dounan, "CHF and dryout point in vertical narrow annuli," Nuclear Engineering and Design, vol. 237, no. 22, pp. 21752182, 2007.

[13] G. P. Celata, K. Mishima, and G. Zummo, "Critical heat flux prediction for saturated flow boiling of water in vertical tubes," International Journal of Heat and Mass Transfer, vol. 44, no. 22, pp. 4323-4331, 2001.

[14] S. Jayanti and M. Valette, "Prediction of dryout and postdryout heat transfer at high pressures using a one-dimensional three-fluid model," International Journal of Heat and Mass Transfer, vol. 47, no. 22, pp. 4895-4910, 2004.

[15] M. Xi, Y. Wu, W. Tian, G. H. Su, and S. Qiu, "The influence of ocean conditions on thermal-hydraulic characteristics of a passive residual heat removal system," Progress in Nuclear Energy, vol. 85, pp. 573-587, 2015.

[16] L. B. Qian, W. X. Tian, S. Z. Qiu, G. H. Su, and Y. Li, "Research on model of additional forces of ocean conditions in onedimensional coolant channel," Nuclear Power Engineering, vol. 33, pp. 104-109, 2012, in Chinese.

[17] M. Lee, "A mechanistic critical heat flux model for subcooled flow boiling based on local bulk flow conditions," International Journal of Multiphase Flow, vol. 14, no. 6, pp. 711-728, 1988.

[18] W. X. Liu, W. X. Tian, Y. W. Wu et al., "An improved mechanistic critical heat flux model and its application to motion conditions," Progress in Nuclear Energy, vol. 61, pp. $88-101,2012$.

[19] M. Xi, W. Tian, S. Huang, G. Su, S. Qiu, and D. Du, "Theoretical analysis of the characteristics of critical heat flux in vertical narrow rectangular channels under motion conditions," in Proceedings of the NURETH-16, Hyatt Regency Chicago, Chicago, IL, USA, August-September 2015.

[20] G. B. Wallis, One-Dimensional Two-Phase Flow, McGrawHill, New York, NY, USA, 1969.

[21] C. W. Gear, Numerical Initial Value Problems in Ordinary Differential Equation, Prentice Hall PTR, Englewood Cliffs, NJ, USA, 1971.

[22] Y. Katto and H. Ohno, "An improved version of the generalized correlation of critical heat flux for the forced convective boiling in uniformly heated vertical tubes," International Journal of Heat and Mass Transfer, vol. 27, no. 9, pp. 16411648, 1984. 